\title{
Comparison of two protocols for maxillary protraction: tooth anchored versus bone anchored protraction facemask
}

Nicole M. DeShon

Follow this and additional works at: https://researchrepository.wvu.edu/etd

\section{Recommended Citation}

DeShon, Nicole M., "Comparison of two protocols for maxillary protraction: tooth anchored versus bone anchored protraction facemask" (2014). Graduate Theses, Dissertations, and Problem Reports. 7310. https://researchrepository.wvu.edu/etd/7310

This Thesis is protected by copyright and/or related rights. It has been brought to you by the The Research Repository @ WVU with permission from the rights-holder(s). You are free to use this Thesis in any way that is permitted by the copyright and related rights legislation that applies to your use. For other uses you must obtain permission from the rights-holder(s) directly, unless additional rights are indicated by a Creative Commons license in the record and/ or on the work itself. This Thesis has been accepted for inclusion in WVU Graduate Theses, Dissertations, and Problem Reports collection by an authorized administrator of The Research Repository @ WVU. For more information, please contact researchrepository@mail.wvu.edu. 


\title{
Comparison of two protocols for maxillary protraction: tooth anchored versus bone anchored protraction facemask
}

\author{
Nicole M. DeShon \\ Thesis submitted to: \\ The School of Dentistry \\ at West Virginia University \\ in partial fulfillment of the requirements for the degree of \\ Master of Science in \\ Orthodontics \\ Peter Ngan, D.M.D., Chair \\ Chris Martin, D.D.S., M.S. \\ Bryan Weaver, D.D.S., M.D. \\ Department of Orthodontics
}

\author{
Morgantown, West Virginia \\ 2014
}

Key Words: maxillary protraction, Class III, hybrid hyrax Copyright 2014 Nicole DeShon 
UMI Number: 1555073

All rights reserved

INFORMATION TO ALL USERS

The quality of this reproduction is dependent upon the quality of the copy submitted.

In the unlikely event that the author did not send a complete manuscript and there are missing pages, these will be noted. Also, if material had to be removed, a note will indicate the deletion.

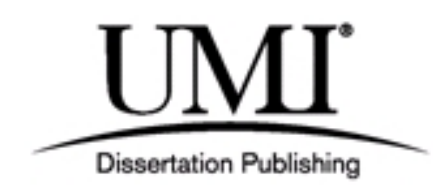

UMI 1555073

Published by ProQuest LLC (2014). Copyright in the Dissertation held by the Author.

Microform Edition () ProQuest LLC.

All rights reserved. This work is protected against unauthorized copying under Title 17, United States Code

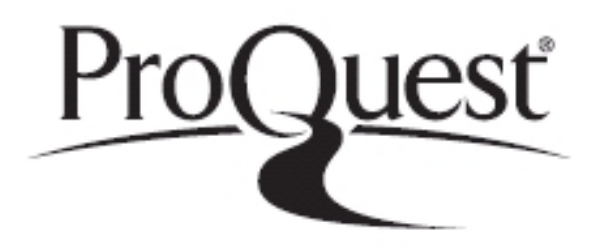

ProQuest LLC.

789 East Eisenhower Parkway

P.O. Box 1346

Ann Arbor, MI 48106 - 1346 


\begin{abstract}
Comparison of two protocols for maxillary protraction: tooth anchored versus bone anchored protraction facemask
\end{abstract}

\author{
Nicole M. DeShon, DMD; Peter Ngan, DMD; Chris Martin, DDS, MS; Bryan Weaver, DDS, \\ MD; Benedict Wilmes, DDS, PhD; Erdogen Gunel, PhD
}

\begin{abstract}
Early orthopedic interventions have been advocated for patients presented with Class III malocclusion. However, many conventional treatment modalities have negative dental changes that accompany the positive skeletal changes. There is a lack of literature on comparing a new hybrid hyrax bone anchored maxillary protraction to conventional tooth anchored maxillary protraction. The objective of this retrospective study is to quantify and compare differences in craniofacial morphology, if any, between patients treated with tooth anchored versus bone anchored maxillary protraction. A total of 40 patients (16 males, 24 females) with Class III malocclusion who had received early orthopedic treatment with tooth anchored maxillary expansion and protraction or with bone anchored hybrid hyrax maxillary expansion and protraction were selected for the study. Lateral cephalograms were taken at the start of phase I treatment (mean age $9.8 \pm 1.6$ for tooth anchored and 9.6 \pm 1.2 for bone anchored) and at the end of maxillary protraction. A custom cephalometric analysis based on variables described by Bjork and Pancherz, Mcnamara, Tweed, Jaraback, and Steiner was used. Data were analyzed using a one-way analysis of variance with $p<0.05$. Significant differences between the two groups were found in 8 out of 37 cephalometric variables after maxillary protraction $(p<.05)$. Subjects in the tooth anchored group had more proclination of maxillary incisors, an increased overjet correction and molar relationship correction, an increased downward movement of A point, a decreased vertical position of the maxillary incisor, a increased opening of the articulare angle (S-Ar-GoI), an increase in mandibular plane (SNL-ML and FH-ML). These results show that there is similar forward movement of A point and the same amount of forward movement of the maxillary molars between the two maxillary protraction modalities. Based on the sum total of these results, the hybrid hyrax bone anchored maxillary protraction may be a better treatment alternative for Class III patients with a hyperdivergent growth pattern.
\end{abstract}




\section{DEDICATION}

To my mother, Magie, you are my world. You have been by my side every step of my journey. Thank you cannot even begin to express my gratitude. You have been my sounding board, my voice of reason, my constant support and rock, and my best friend. Without your wisdom, guidance, and sacrifices, I would never have gotten this far. I love you and I thank you more than words can say.

To my brother, Joe, thank you for your encouragement and your unfailing support. I am proud of all that you have accomplished. I cannot ask for a better sibling than you.

To my co-resident, Deepa, who has been my constant companion for nearly three years. You are the sister I would choose for myself. Thank you for being my partner in crime, my teacher and my friend. I will miss you so much.

To my family and friends, who touch my life in so many wonderful ways, thank you for your continued love and support. 


\section{ACKNOWLEDEMENTS}

Dr. Peter Ngan. Thank you for your guidance and support for this project and this program. You lead the department by example with hard work, humor, caring, respect, positive attitude, and kindness. Thank you for giving me a chance to fulfill a dream.

Dr. Chris Martin. Thank you for your help on both this project and the clinic the past few years. You were always there to see any of our patients and it was much appreciated.

Dr. Bryan Weaver. Thank you for being on my committee and also your help on this project, especially when I was trying to figure out magnification for different $\mathrm{x}$-ray machine.

Dr. Benedict Wilmes. Thank you for your generosity on allowing me to use your clinical records for this project.

Dr. Erdogan Gunel. Thank your help on the statistical analysis of the data.

Dr. Timothy Tremont. Thank you for your help and allowing me to use your patient records for this project and your dedication to teaching. You have shaped me and proven to be an invaluable resource.

Drs. Hazey, McFarland, Kirsch, Sebbahi, Jarrett, Foley, Boyles, Little, Wright, Dempsey. Thank you for your time and dedication to this program. You are a great example to the young orthodontic. What you have taught in this program is cutting edge and applicable to everyday orthodontics. You contribute the backbone of this program. Everything you do is much appreciated.

Karen, Leona, Sandy, Carrie, Hillary. Thank you for your support and putting up with my requests for the past three years. I will miss you and wish the best for you in the future.

Deepa and Lance. Thank you for your friendship and support. I will miss the trips we have had together. Thank you for making this residency experience unforgettable.

Jen, Travis, Nick, Tim, Jason, and Martin, as well as former residents Holly, Jung-Mee, and Ronnie. Thank you for all the good times and laughs on our traveling and in the clinic. Thank you for your support. Good luck to you in the future. 


\section{Table of Contents}

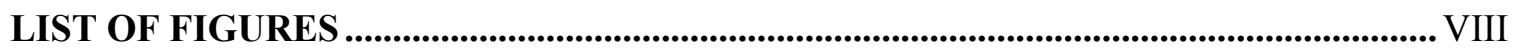

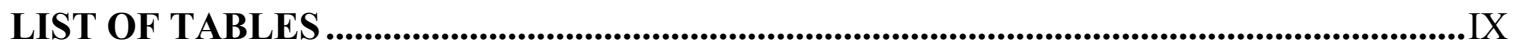

CHAPTER I: INTRODUCTION ............................ERROR! BOOKMARK NOT DEFINED.1

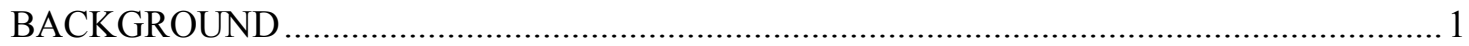

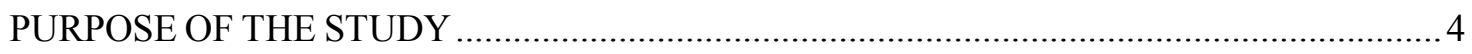

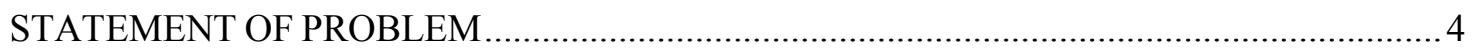

SIGNIFICANCE OF THE PROBLEM ..............................ERROR! BOOKMARK NOT DEFINED.

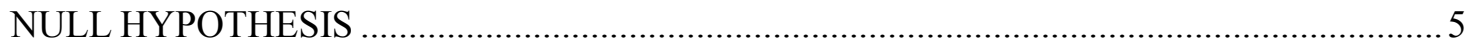

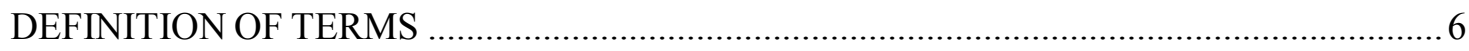

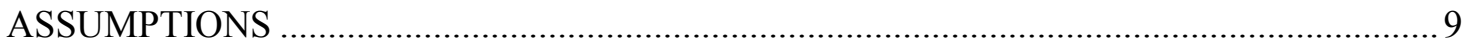

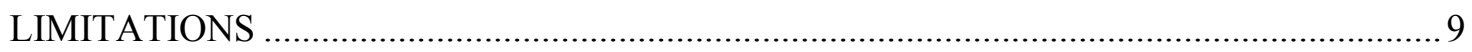

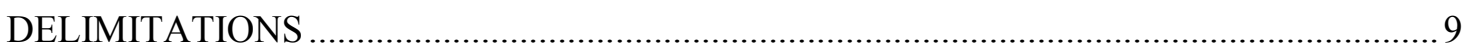

CHAPTER II: LITERATURE REVIEW ....................................................................................... 10

HISTORY AND CLASSIFICATION OF MALOCCLUSION ........................................... 10

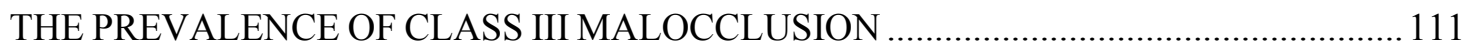

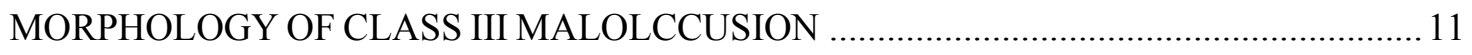

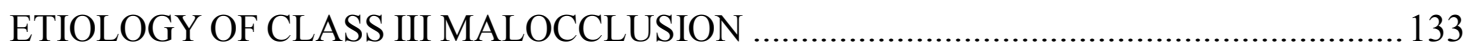

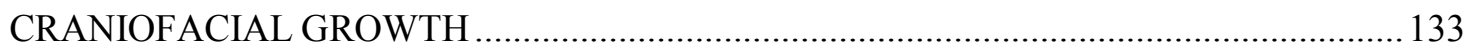

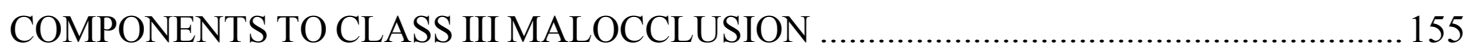

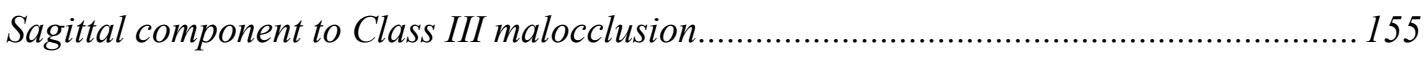

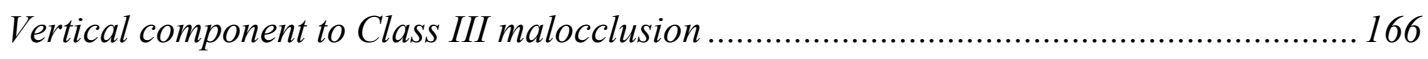

Transverse component to Class III malocclusion ........................................................... 16

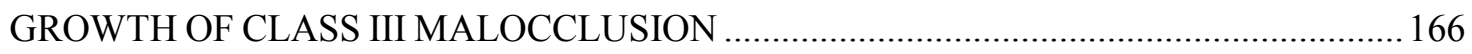

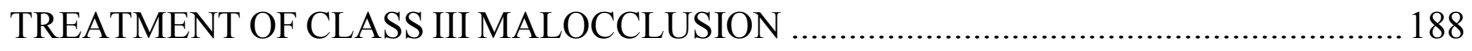




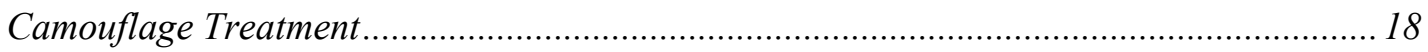

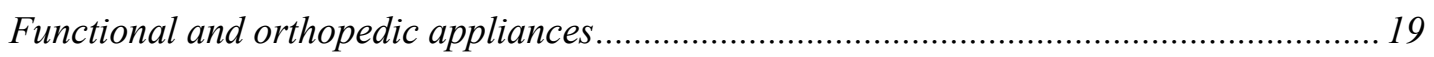

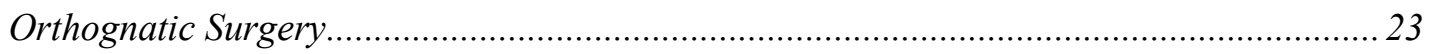

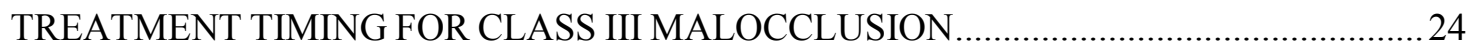

CHAPTER III: MATERIAL AND METHODOLOGY ...........................................................22

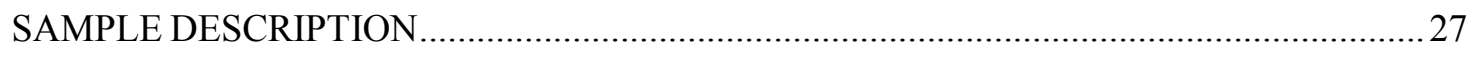

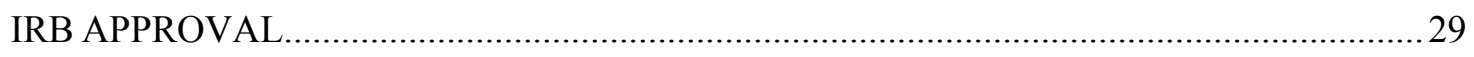

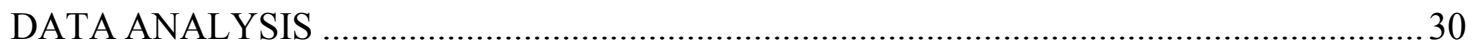

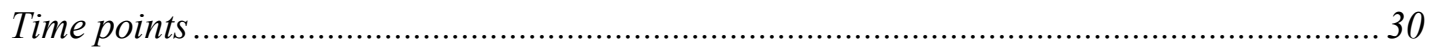

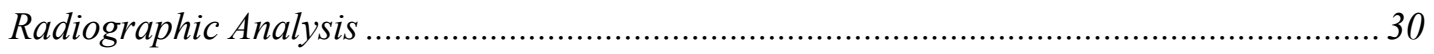

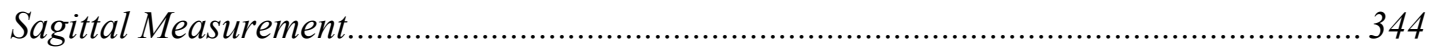

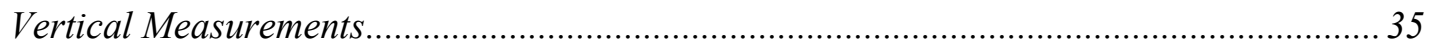

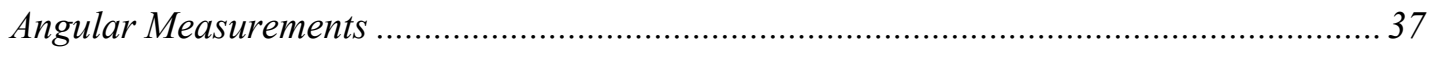

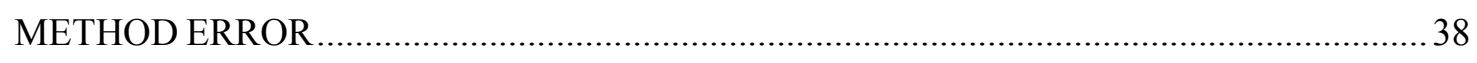

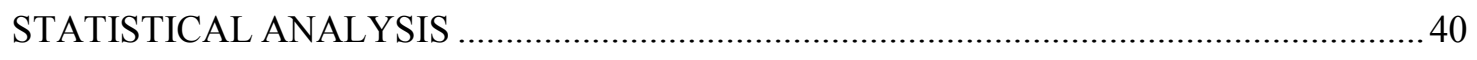

CHAPTER IV: RESULTS ............................................................................................................... 411

AGE AND SEX DISTRIBUTION .................................RROR! BOOKMARK NOT DEFINED.41

COMPARISON OF CRANIOFACIAL MORPHOLOGY BEFORE TREATMENTERROR!

BOOKMARK NOT DEFINED....42

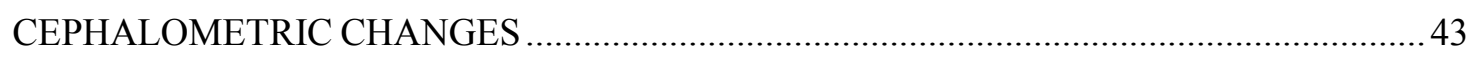

CALCULATION OF OVERJET AND MOLAR RELATIONSHIP CHANGESERROR! BOOKMARK NOT DEFINED.49

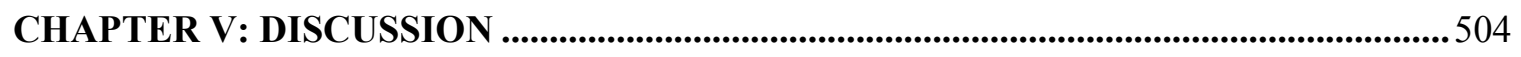

CHAPTER VI: SUMMARY AND CONCLUSIONS ......................................................56

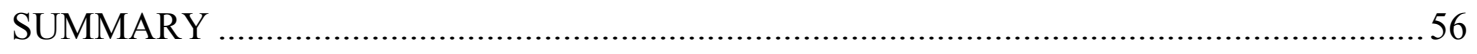




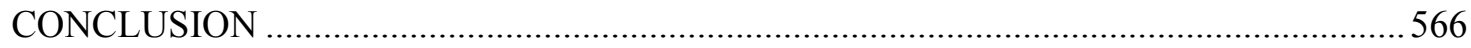

CHAPTER VII: RECOMMENDATION FOR FUTURE RESEARCHES ........................588

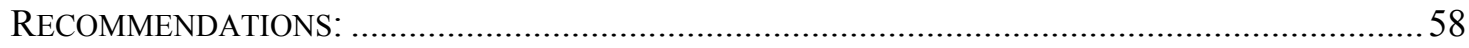

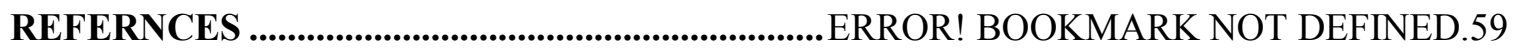

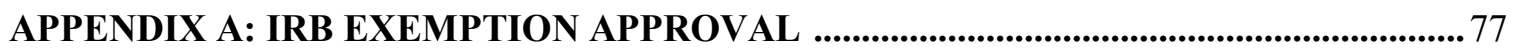




\section{LIST OF FIGURES}

Figure 1. Hybrid Hyrax Appliances ......................................................................... 28

Figure 2. Skeletal and Dental Landmarks ................................................................ 31

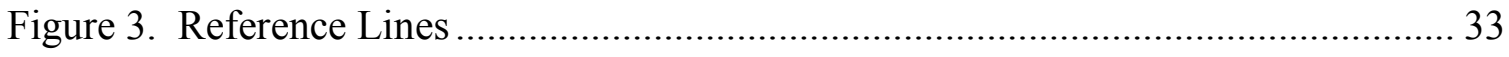

Figure 4. Reference Grid and Landmarks Used in Sagittal MeasurementsError! Bookmark not defined. 34

Figure 5. Landmarks Used in Vertical Measurements....................................................... 36

Figure 6. Landmarks Used in Angular Measurements............................................ 37

Figure 7. Skeletal and Dental Contributions to Overjet correction for Tooth Anchored Group..50

Figure 8. Skeletal and Dental Contributions to Overjet correction for Bone Anchored Group...51

Figure 9. Skeletal and Dental Contributions to Molar Relationship correction for Tooth Anchored

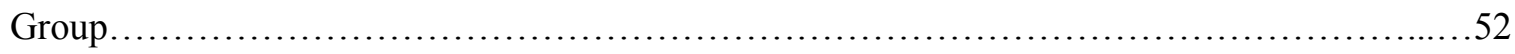

Figure 10. Skeletal and Dental Contributions to Molar Relationship correction for Bone Anchored Group. .53 


\section{LIST OF TABLES}

Table 1. Prevalance of Maxillary and Mandibular Anteroposterior Deficiency ............. 12

Table 2. Symbols for Different Time Intervals...................................................... 30

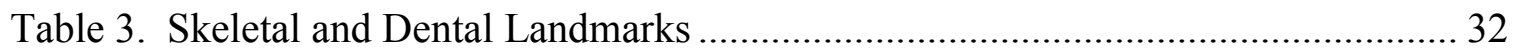

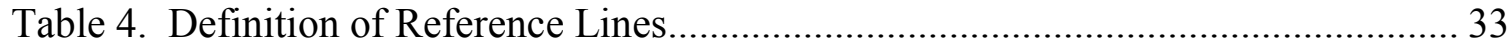

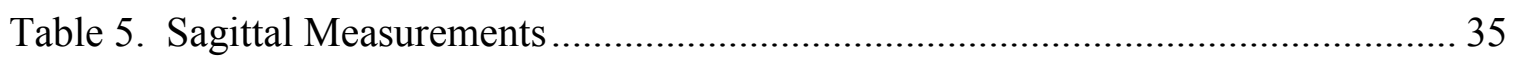

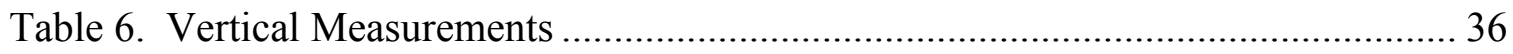

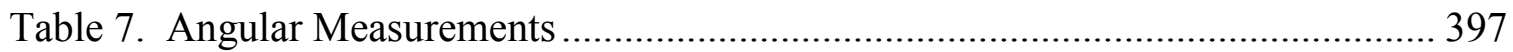

Table 8. Correlation Coefficients for Sagittal, Vertical, Angular Measuremetns .... Error!

Bookmark not defined.39

Table 9. Age and Sex Distribution. 41

Table 10. Comparison of Craniofacial Morphology before TreatmentError! Bookmark not defined. 42

Table 11. Sagittal Measurements at t0 and t1 in Control Group .... Error! Bookmark not defined. 43

Table 12. Vertical Measurements at t0 and t1 in Control Group ... Error! Bookmark not defined.43

Table 13. Angular Measurements at $\mathrm{t} 0$ and $\mathrm{t} 1$ in Control Group ... Error! Bookmark not defined. 44

Table 14. Sagittal Measurements at $\mathrm{t} 1$ and $\mathrm{t} 2$ in Tooth Anchored GroupError! Bookmark not defined. 44

Table 15. Vertical Measurements at $\mathrm{t} 1$ and $\mathrm{t} 2$ in Tooth Anchored GroupError! Bookmark not defined. 45 
Table 16. Angular Measurements at $\mathrm{t} 1$ and $\mathrm{t} 2$ in Tooth Anchored Group

Table 17. Sagittal Measurements at T1 and T2 in Bone Anchored Group Error! Bookmark not defined. 46

Table 18. Vertical Measurements at T1 and T2 in Bone Anchored GroupError! Bookmark not defined.46

Table 19. Angular Measurements at T1 and T2 in Bone Anchored Group Error! Bookmark not defined. 47

Table 20. Compaison of Mean Difference between Tooth Anchored and Bone Anchored Groups Error! Bookmark not defined.48

Table 21. Calculation of Overjet and Molar Correction 1249 


\section{CHAPTER I: INTRODUCTION}

\section{BACKGROUND}

Treatment of skeletal Class III malocclusion is one of the most challenging problems faced by orthodontists, especially since there are variable responses to treatment and differences in growth of patients with Class III malocclusion. The prevalence of the malocclusion varies among different ethnic groups, with individuals of Asian ancestry having the highest prevalence of $5-22 \%{ }^{1-5}$ and individuals of European or North American descent ranging from $1 \%$ to $12 \%{ }^{3,6,7}$.

A developing class III malocclusion can include both skeletal and dentoalveolar components. Skeletally, a Class III patient can exhibit maxillary retrusion, mandibular protrusion, or a combination of both $^{8-11}$. Reports show that two-thirds of skeletal Class III malocclusions are due to either maxillary retrognathism or a combination maxillary retrognathism and mandibular prognathism ${ }^{12-15}$.

Angle characterized Class III malocclusions as having the mesiobuccal cusp of the permanent maxillary first molar occluding distal to the buccal groove of the permanent mandibular first molar. These patients also often present with negative overjet, proclined maxillary incisors, retroclined mandibular incisors, a posterior or anterior crossbite, narrow nasal cavity, prominent chin, and midface

deficiency ${ }^{3-5,11,16}$. Moreover, there are complex interactions of genetic and environmental factors, which may act synergistically or in isolation, or may cancel each other out ${ }^{16}$. Contributions from the cranial base, maxilla, mandible, position of temporomandibular joint, and inclination of the dentition to the malocclusion have all been documented in the literature ${ }^{15,17-19}$.

To date, there are three treatment options for Class III patients: orthopedic treatment with or without comprehensive orthodontic treatment, orthodontic camouflage, and surgical correction in conjunction with orthodontic treatment. A number of these orthopedic devices focus on treating the 
patients in the early mixed dentition period since literatures have reported that an early correction of the malocclusion allows for a favorable growth environment for dentofacial development and may help prevent more severe malocclusion in late adolescence ${ }^{20,21}$. Early treatment using protraction facemask therapy in conjunction with a rapid maxillary expansion appliance has been shown to be successful in correcting skeletal Class III malocclusions that are due primarily to deficient maxillary development ${ }^{15,20,22}$.

The rationale of maxillary protraction with a facemask is to apply an anteriorly directed force on the maxilla. The forces generated act indirectly on the circummaxillary sutures, which are still patent at an early age, and thereby stimulate bone apposition in the suture areas. The goal of combining the rapid maxillary expansion appliance with the protraction face-mask is to provide a more effective protraction of the maxilla by aiding in disarticulating the circummaxillary sutures to facilitate forward movement of the $\operatorname{maxilla} a^{3,5,8,21}$.

Conventional protraction facemask therapy, with an indirect application of force to the sutures through tooth borne anchorage, causes both skeletal and dental changes in the maxilla and the mandible. Ideally the direction of force is applied through the center of resistance of the maxilla, which occurs between orbitale and the mesiobuccal cusp of the maxillary first molar ${ }^{23-25}$. Correction of the Class III malocclusion occurs as a result of forward and downward movement of the maxilla, downward and backward rotation of the mandible, labial tip of the maxillary incisors, and lingual tip of the mandibular incisors. This is usually accompanied by an increase in lower face height and a decrease in overbite ${ }^{26-29}$.

The goal of protraction facemask therapy is to obtain major skeletal changes and minimum undesirable dental effects. Previous studies have shown that traditional tooth anchored protraction facemask devices have a loss in anchorage $\mathrm{e}^{30,31}$. Researchers have noted excessive forward movement and extrusion of maxillary molars, excessive proclination of the maxillary incisors, and an increase in lower face height. This excessive forward movement of the maxillary dentition is a concern especially in 
situations in which preservation of arch length is necessary ${ }^{30,31}$. To obtain maximum skeletal changes and minimize undesirable dental effects, it would be reasonable to take advantage of stable skeletal anchorage to transfer the force directly to the circummaxillary sutures.

In this regard, researchers have attempted to design an absolute anchorage system for maxillary protraction $^{32}$. These newer treatment modalities include the use of intentionally ankylosed maxillary deciduous canines $^{33}$, osseointegrated titanium implants ${ }^{34,35}$, onplants ${ }^{35}$, miniscrews ${ }^{36-38}(58)$ and most recently miniplates ${ }^{32,39-46}$. Each implants system has strengths and weaknesses. Because of the wellknown problems caused by tooth anchored expansion devices, such as buccal tipping, gingival recessions or root damage, techniques have been described based on pure bone anchored RPE devices ${ }^{47}$. Besides the high surgical invasiveness for insertion, they may also cause root lesions and infections ${ }^{47}$. As a consequence, distractors of this type have not become a standard device. Sar $^{48}$ describes a technique using miniplates at the lateral nasal wall that are hooked to a protraction facemask to obtain pure skeletal anchorage. This technique also has a high surgical invasiveness, and it does not include an RPE in the design.

To minimize the surgical invasiveness of the pure bone anchored devices, Wilmes et al have introduced the hybrid hyrax, a tooth and bone anchored expander ${ }^{37,49}$. Two mini-implants are placed in the anterior palate and an expansion device is connected to the mini-implants and to the first molars. After expansion the patient undergoes facemask therapy with elastics attached to hooks on the hybrid hyrax. In his initial study, Wilmes found this device to be effective for expansion, and was thought to minimize mesial migration of the dentition when used in conjunction with protraction facemask ${ }^{37}$.

The literature presents several studies or case reports that compare the results from bone anchored protraction facemask therapy to results from conventional tooth borne protraction facemask therapy ${ }^{39,41,48}$. To date no literature has been presented comparing the results of the hybrid hyrax bone anchored maxillary expansion and protraction to tooth anchored maxillary expansion and protraction. The purpose 
of this study is to compare results from tooth anchored protraction facemask and bone anchored protraction facemask, and quantify skeletal and dental contributions.

\section{PURPOSE OF THE STUDY}

The objective of this study is to quantify and compare skeletal and dental changes between tooth anchored and bone anchored maxillary protraction in Class III patients, as determined from lateral cephalogram radiographs. Sagittal, vertical and angular variables will be analyzed to determine skeletal and dental changes.

\section{STATEMENT OF THE PROBLEM}

The literature presents a few studies or case reports that compare the results from bone anchored protraction facemask therapy to results from conventional tooth anchored protraction facemask therapy $y^{39,41,45,48}$. To date, no study has been done with the hybrid hyrax appliance in a controlled environment. Wilmes' study did not determine dental and molar contributions from the appliance, and it did not compare the hybrid hyrax results to a conventional tooth anchored facemask group ${ }^{37}$. This study will use the Pitchfork analysis to determine dental and skeletal contributions to overjet correction and molar relationship correction ${ }^{50}$. This study will attempt to determine if bone anchored protraction facemask is more effective and has less negative side effects than traditional tooth anchored protraction facemask therapy.

\section{SIGNIFICANCE OF THE PROBLEM}

Being able to choose a treatment modality that significantly improves the patient's malocclusion with minimum negative side effects is ideal. This research will look for a significant difference in skeletal and dental measurements between the bone anchored and the tooth anchored protraction methods. 
Results of this study will help clinicians in choosing an effective treatment modality for their Class III patients.

\section{NULL HYPOTHESIS}

1. There is no difference in treatment effects for sagittal variables between the tooth anchored and bone anchored protraction facemask groups.

2. There is no difference in treatment effects for vertical variables between the tooth anchored and bone anchored protraction facemask groups.

3. There is no difference in treatment effects for angular variables between the tooth anchored and bone anchored protraction facemask groups.

\section{DEFINITION OF TERMS}

1. Class III Malocclusion: Mesial (anterior) relationship of the lower first molar to the upper, a retruded relationship of the upper first molar to the lower, or a combination of the two. The mesiobuccal cusp of the upper first molar will typically occlude near the embrasure between the lower first and second molars.

2. Centric Occlusion: The relationship between upper and lower teeth in normal full functional closure.

3. Centric Relation: The relation between upper and lower teeth when both mandibular condyles are fully seated in their fossae in optimum functional positions.

4. Cephalogram: A term sometimes used as a synonym for cephalometric radiograph

5. Cephalometric analysis: An evaluation of dental and related skeletal relationships based on measurements of cephalometric radiographs.

6. Cephalometric radiograph: A radiograph of the head made with precise reproducible relationships between x-ray source, subject and film. The generally accepted distances between 
$\mathrm{x}$-ray source and the center of the subject are 5 feet or $150 \mathrm{~cm}$. The distance between subject and film is usually $15 \mathrm{~cm}$, but may be standardized at a different value or varied with patient size and recorded for each exposure. The two standard orientations are lateral (profile) and posteroanterior (P-A).

7. Cephalometric tracing: A tracing of selected structures from a cephalometric radiograph, made on translucent drafting paper or digitized on computer software for purposes of measurement and evaluation.

8. Comprehensive Orthodontic Therapy: A coordinated approach to improvement of the overall anatomic and functional relationships of the dentofacial complex, as opposed to partial correction with more limited objectives such as cosmetic improvement. Comprehensive orthodontic treatment, usually, but not necessarily, utilizes fixed orthodontic attachments as one treatment modality. May be coordinated with adjunctive procedures (such as extractions, maxillofacial surgery, or other dental services) directed at malrelationships within the entire dentofacial complex.

9. Crossbite: an abnormal relationship of a tooth or teeth to the opposing teeth, in which normal buccolingual relationships are reversed.

10. Deep Bite: Excessive overbite; closed bite

11. Distal: A direction oriented along the dental arch away from the dental midline; right or left in the anterior segment, posteriorly in the buccal segments.

12. Facial Concavity: a term applied to the analysis of a profile. An inwardly rounded curve from forehead to the lips to the chin. A concave facial profile is often associated with a Class III malocclusion.

13. Hyrax Expander: Banded rapid maxillary expansion appliance with an expansion screw in close proximity to the palatal contour, bands on first molars and often first premolars, and lingual support wires added for rigidity. 
14. Hybrid Hyrax Expander: A bone anchored and tooth anchored expansion device attached to two mini-implants in the anterior palate and to the first molars.

15. Labial: Of or pertaining to the lip. Also used to identify a surface facing the lips or a direction toward the lips.

16. Lingual: Of or pertaining to the tongue. Used to describe surfaces and directions facing the tongue.

17. Malocclusion: A deviation in intramaxillary and/or intermaxillary relations of teeth that presents a hazard to the individual's well-being. Often associated with other dentofacial deformities.

18. Maxillary expansion: Separation of the two halves of the maxilla achieved in the growing individual with the use of an orthopedic expansion device.

19. Mesial: Toward or facing the midline, following the dental arch. Used to describe surfaces of teeth as well as direction.

20. Mixed Dentition: the developmental stage during which both deciduous and permanent teeth are present in the mouth (approximately 6 to 12 years of age).

21. Orthodontic appliance: any device used for the purpose of influencing tooth position.

22. Occlusion: The relationship of the maxillary and mandibular teeth as they are brought into functional contact.

23. Overbite: Vertical overlapping of upper teeth over lower teeth, usually measured perpendicular to the occlusal plane

24. Overjet: Horizontal projection of upper teeth beyond the lower teeth, usually measured parallel to the occlusal plane.

25. Proclination: Anterior angulation of anterior teeth, as opposed to protrusion, which indicates positional variation.

26. Prognathic: A forward relationship of the maxilla or mandible relative to the craniofacial skeleton. 
27. Protraction facemask: An extraoral appliance used to exert a forward and downward vector of force on the maxilla. Also referred to as reverse protraction headgear.

28. Pseudo Class III malocclusion: Relationship in which a Class I skeletal pattern, normal facial profile, and Class I molar relation may occur in centric relation, but a Class III skeletal and dental pattern are observed in centric occlusion.

29. Retroclination: Posterior angulation of anterior teeth.

30. Retrognathic: The condition of the maxilla or mandible that is posterior to its normal relationship relative to the craniofacial skeleton.

31. Retention: The passive treatment period following active orthodontic correction during which retaining appliances may be used.

32. Skeletal Class III malocclusion: Skeletal relationship in which either the mandible is prognathic, the maxilla is retrognathic, or a combination of the two.

33. Tipping: Tooth movement, either spontaneous or therapeutic, in which the angulation of the long axis of the root is changed.

34. Temporomandibular Joint: One of the two paired articulations between the temporal bones and the mandible; the condylar process of the mandible articulates in the articular fossa of the temporal bone.

35. WITS: A measurement used to describe the severity of jaw disharmony. It is measured by drawing a line from the functional occlusal plane (OP) to Point A and also a line from the functional occlusal plane to Point B. The wits measurement is the distance between Point A and Point B on the OP. The projections from points A and B will intersect the occlusal plane at nearly the same point if the jaws are harmonious anteroposteriorly.

36. Centric Relation (CR): The mandibular jaw position in which the head of the condyle is situated as far anterior and superior as it possibly can within the mandibular fossa. 


\section{ASSUMPTIONS}

1. Cephalometric radiographs taken with different machines at different times can be compared by adjusting the magnification.

2. Cephalometric measurements can be utilized to evaluate growth.

3. Orthopedic forces can modify growth of the maxilla and mandible.

4. The lateral cephalograms for the treated and control groups were taken with the subjects in centric occlusion.

5. Growth between the treatment groups is similar

\section{LIMITATIONS}

1. Samples in the two groups were not selected at random.

2. The sample was selected from two different pools of patients: from the private practice of Dr. Benedect Wilmes, Dusseldorf, Germany, and the files of the Post-Doctoral Orthodontic clinic at West Virginia University.

3. It was assumed that since different $\mathrm{x}$-ray units were used to collect data, all the magnification error were accounted for.

4. Gender differences amongst patients

5. Ethnicity differences amongst patients

6. Health history differences amongst patients

7. Cooperation differences amongst patients/parents

\section{DELIMITATIONS}

1. One researcher will perform all the cephalometric tracings, measurements, and recordings.

2. Subjects will be delimited to the inclusion criteria as defined in the Materials and Methods section.

3. The study will be retrospective. 


\section{CHAPTER II: LITERATURE REVIEW}

\section{HISTORY AND CLASSIFICATION OF MALOCCLUSION}

Mal-alignment of the teeth and jaws, and the use of primitive appliances used to correct these problems, can be found in both Greek and Etruscan cultures ${ }^{51}$. When Edward Angle developed the classification of occlusion late 1800's the focus changed from treating the esthetics of the tooth and jaw problems to treating the actual dental occlusion ${ }^{51}$.

Angle's definition of occlusion is focused on relationship between the mesiobuccal cusp of upper first molar and opposing lower molar ${ }^{52}$. Four classifications were made:

1. Normal occlusion: the mesiobuccal cusp of the maxillary first molars occludes with the buccal groove of the mandibular first molar and the teeth are arranged on a smoothly curving line of occlusion.

2. Class I malocclusion: the mesiobuccal cusp of the maxillary first molar occludes with the buccal groove of the mandibular first molar but discrepancies exist in the line of occlusion.

3. Class II malocclusion: the mesiobuccal cusp of the maxillary first molar is mesial to the buccal groove of the mandibular first molar.

4. Class III malocclusion: the mesiobuccal cusp of the maxillary first molar is distal to buccal groove of the mandibular first molar.

Many additions have been made to the classification system since it was introduced. As time went on, the classification system was used to describe other factors instead of just the molar relationship. Although many shortcomings exist within the Angle's classification of occlusion, it is still currently the most widely adapted description of occlusion.

In the 1920's, the development of cephalometric radiography allowed orthodontists to evaluate changes that occurred in tooth and jaw positions due to growth or treatment ${ }^{53}$. This tool showed that 
Class II or Class III malocclusions are frequently the result of skeletal discrepancies instead of just malpositioned teeth, and that these skeletal discrepancies can be modified by orthodontic/orthopedic treatment. As a result, development of orthopedic appliances to modified growth flourished. Today both orthopedic appliance alone or orthopedic appliances in conjunction with fixed appliances are used as a part of comprehensive orthodontic treatment.

\section{THE PREVALENCE OF CLASS III MALOCCLUSION}

The prevalence of Class III malocclusion varies greatly among different ethnic groups, with the highest being among the Asian population ranging from 5\%-22\% $\%^{1,3,4,30,54}$. Prevalence of Class III malocclusion among Caucasian is relatively low compared to other classes of malocclusion. It was reported that the incidence of Class III malocclusion ranges from $1 \%$ to $12 \%$ for white people of European or North American ancestry ${ }^{3,7,55}$. In U.S. studies of African American population groups, the prevalence of Class III malocclusion was reported to be about $6.3 \%{ }^{56}$. Among Hispanic population in North America, the incidence was reported to be approximately $8.3 \%{ }^{57,58}$.

\section{MORPHOLOGY OF CLASS III MALOLCCUSION}

Patients with Class III malocclusion may present with different combinations of abnormal skeletal patterns. Individuals with true Class III skeletal pattern have their mandible naturally positioned

more forward to the face/maxilla without incisal interference ${ }^{10,23}$. This skeletal pattern can be a result of maxillary retrusion, mandibular prognathism, or a combination of both. Table 1 lists the frequency of each combination of skeletal components of a Class III malocclusion, as reported by Ellis and McNamara ${ }^{8}$. 


\begin{tabular}{|c|c|c|c|}
\hline Group & Maxilla & Mandible & Percentage \\
\hline I & Retrusive & Protrusive & $30.1 \%$ \\
\hline II & Retrusive & Neutral & $19.5 \%$ \\
\hline III & Neutral & Protrusive & $19.2 \%$ \\
\hline IV & Protrusive & Protrusive & $14.9 \%$ \\
\hline V & Retrusive & Retrusive & $7.9 \%$ \\
\hline VI & Neutral & Neutral & $4.6 \%$ \\
\hline VII & Neutral & Retrusive & $1.6 \%$ \\
\hline VIII & Protrusive & Neutral & $1.6 \%$ \\
\hline IX & Protrusive & Retrusive & $0.33 \%$ \\
\hline
\end{tabular}

Table 1. Prevalance of Maxillary and Mandibular Anteroposterior Deficiency

Based on the results found in Table 1, a retrusive maxilla and protrusive mandible was the most prevalent skeletal combination in Class III malocclusion. A study conducted by Guyer and colleagues(T 5) reported similar results in that $25 \%$ of the 144 Michigan children, who were between the ages of 5 and 15 years and had a Class III malocclusion with a retrusive maxilla and a protrusive mandible ${ }^{23}$.

Patients with Class III malocclusion tend to have Angle Class III molars and canines, proclined maxillary incisors, retroclined mandibular incisors, and decreased overbite. In addition, anterior crossbite or an edge-to-edge incisor relationship is frequently observed among Class III patients. For some of these patients, proclination of mandibular incisors and retroclination of maxillary incisors can cause posturing of the mandible in an anterior position due to incisal interference. This is a condition known as pseudoClass III malocclusion and is really a Class I malocclusion.

Soft tissue appearance wise, patients will Class III malocclusion often have a straight to concave profile $^{8,59}$. The midface appears retrusive relative to the mandible, and the tip of the chin and the lower lips often lie somewhere in front of a vertical line drawn from nasion, perpendicular to the Frankfort Horizontal plane $\mathrm{e}^{23,60}$. The nasolabial process is often acute, with upper lip appearing more retrusive than the lower $\operatorname{lip}^{8}$. 
Common features found in cephalometric analysis include a shortened anterior cranial base, acute cranial base angle, obtuse gonial angle, an anteriorly positioned glenoid fossa, proclined maxillary incisors and retroclined mandibular incisors, and occasionally increased lower anterior facial height ${ }^{15,19,23}$.

In summary, Class III malocclusion can be due to retrusive maxilla, prognathic mandible, or a combination of both. Patients with Class III malocclusion may present with different combinations of abnormal dental and skeletal patterns. The end result of skeletal headform depends on the extent of the imbalances and the number and extent of counteracting features ${ }^{60}$.

\section{ETIOLOGY OF CLASS III MALOCCLUSION}

Genetics, function, environmental factors, congenital deformities, and size and position of bones have all been shown to play a role in Class III skeletal growth. Several human studies that focus on the role of genetics with regards to Class III malocclusion support the claim that growth and size of the mandible can be hereditary ${ }^{24-26}$. A recent paper by Chang noted the findings of a gene associated with mandibular prognathism ${ }^{27}$. In additional to genetics, environmental factors have also been identified that can contribute to mandibular prognathism. Rakosi and Schilli reported that individuals who have mandibular postural habits to facilitate breathing, or those who are mouth breathers, can present with Class III malocclusion due to tongue posture ${ }^{61}$. Discontinuation of the habit can lead to self-correction. Rakosi and Schilli also noted that occlusal interferences, including negative overjet, may alter mandibular growth and the shape of the mandible ${ }^{61}$. Congenital deformities such as cleft palate and the repair surgeries associated with these deformities can lead to a Class III malocclusion due to restriction of maxillary growth from scar tissues in the maxilla ${ }^{28,62}$.

\section{CRANIOFACIAL GROWTH}

In order to assess the growth of Class III malocclusions, one must review facial growth. The bones of the craniofacial skeleton all begin with mesenchymal bone formation in the early fetal 
development, with exception of the cranial base, nasal septum, and condyle of the mandible, which undergo endochondral growth ${ }^{60}$. Soft tissue growth around craniofacial skeleton stimulates formation of these bones, and subsequently morphology of the face develops. A main growth mechanism for craniofacial skeletal, especially in the cranium and the midface is sutural growth ${ }^{57}$. As tension develops between the sutures, with the advancing soft tissues, bony apposition takes place. In conjunction to sutural growth, there is also continual bony remodeling consisting of both apposition and resorption. These processes are extremely variable and give individual face its unique characteristics. The process of sutural growth takes place into late adolescent years and bony remodeling continues throughout life ${ }^{60}$.

A developing craniofacial skeleton can be thought of as a series of parts relating to and affecting each other. In an individual with no skeletal discrepancy, growth of each part of the facial skeletal complements each other so that the face remains in harmonious proportion. In orthodontics, a main concern is the maxillo-mandibular relationship and its effect on the facial structures. Two of the major factors in this maxillo-mandibular relationship are the growth of both these bones and how they relate to each other in all three planes of space (sagittal, vertical, and transverse) ${ }^{57}$. Growth of the nasomaxillary complex takes place primarily through apposition of bone at the sutures between the cranium and maxilla, resulting in a forward and downward displacement ${ }^{60}$. A non-harmonious facial pattern develops if the nasomaxillary complex exhibits deficient growth in either direction compared to the mandible.

Growth of the mandible takes place by deposition and resorption in a posterior and superior direction. As a result, the condyle grows toward the glenoid fossa and displaces the entire mandible in a forward and downward position to complement the maxilla ${ }^{57}$. Rotation of the mandible can also affect mandibular position relative to the maxilla. In Bjork's implant study, he broke down the growth rotation of the mandible into three components: total rotation, matrix rotation, and intramatrix rotation ${ }^{63}$. Total rotation is rotation of the mandibular core relative to the cranial base. Intramatrix rotation is the rotation of mandibular plane relative to the core of mandible. Matrix rotation equals total rotation minus intramatrix rotation, which is rotation of the mandibular plane relative to cranial base. These factors 
along with the condylar growth pattern result in the final position of the mandible. Bjork states that there is no said pattern leading to facial harmony ${ }^{63}$. Rather, there are an infinite number of combinations of condylar growth, matrix and intramatrix rotations that lead toward normal facial balance and occlusion. What is important is how each part responds to the other concurrently.

\section{COMPONENTS TO CLASS III MALOCCLUSION}

\section{Sagittal component to Class III malocclusion}

Various investigators have reported that anterior cranial base length is shorter in Class III individuals compared to ones with normal occlusion ${ }^{29,64}$, thereby establishing a foreshortened maxillary arch. There are also reports that an acute cranial base angle was correlated with skeletal Class III malocclusion ${ }^{31,64,65}$. This more acute flexure of the cranial base affects the position of glenoid fossa, which consequently results in a more anteriorly positioned mandible ${ }^{66}$. A large-scale longitudinal study done by Miyajima on the growth of 1376 untreated Class III Japanese females found that the maxilla of these patients was in a retruded position when compared to the cranial base ${ }^{67}$. In agreement, Guyer and Ellis also found that majority of Caucasian individuals in North America with skeletal Class III malocclusion have maxillary retrusion ${ }^{8,23}$. Pure mandibular prognathism can also occur in Class III malocclusion, but appears to be less common compared to maxillary retrusion or a combination of maxillary retrusion and mandibular prognathism. Another feature commonly found in Class III malocclusions is that Class III patients tend to have significantly more anteriorly positioned condyles ${ }^{29,68}$. Not surprisingly, Baccetti reported also that the position of the temporomandibular joint is more anteriorly located for skeletal Class III subjects ${ }^{68}$. Therefore, anterior displacement of temporomandibular joint landmarks such as articulare is one feature of the Class III mandibular morphology. 


\section{Vertical component to Class III malocclusion}

Class III individuals can be hyperdivergent and have excessive vertical facial heights or hypodivergent with decreased lower facial heights ${ }^{57}$. The treatment of these differing vertical growth patterns can be very different. Wolfe examined serial cephalograms of Class III subjects compared to matched Class I control group and found that in comparison to Class I subjects, those with Class III maloclussion have larger mandibular plane angles, increased gonial angles, and increased lower face height ${ }^{17}$. In a study examining growth in Class III individuals, Reyes compared 949 cephalometric radiographs to norms established by the Michigan Growth Study ${ }^{15}$. While noting mandibular length increases were larger during this interval than the norm, Reyes also stressed that lower anterior facial height was significantly larger during the later developmental stages ${ }^{15}$. Sato also noted that Class III individuals usually have steep mandibular plane angles and obtuse gonial angles ${ }^{69}$. Because of its effect on the occlusal plane, vertical component of an individual is an important factor in the development of a skeletal Class III malocclusion.

\section{Transverse component to Class III malocclusion}

The third dimension to consider in examining the morphology of Class III individuals is the transverse parameter. Various studies compared maxillary transverse dimension of individuals with Class III malocclusion to individuals with normal occlusion and found that the intermolar width and maxillary skeletal base widths were decreased in Class III individuals as compared to Class I individuals, and that this deficiency worsened with age $\mathrm{e}^{70-72}$. Franchi, Baccetti found similar results in there study comparing Class II and III individuals to Class I norms ${ }^{73}$. Mandibular intercanine and intermolar alveolar widths were found to be significantly larger in Class III individuals as well ${ }^{72}$.

\section{GROWTH OF CLASS III MALOCCLUSION}

Research done by Mitani studying growth of Japanese Class III individuals during pre-pubertal, pubertal, and post-pubertal period found that morphological pattern of the prognathic face associated with 
excess mandible is established early in life $\mathrm{e}^{10,74}$. For these individuals, the increment of growth is relatively similar to those with Class I skeletal pattern and that the original proportion between maxilla and mandible remain relatively constant. In contrast, a study done by Miyajima found that the maxillas of the patients examined in the study were in a retruded position when compared to the cranial base, and this did not worsen with time ${ }^{67}$. However, a mandible that was protrusive in the early developmental groups worsened through puberty. Consequently, the maxillo-mandibular jaw discrepancy became worse. This study also noted that dental compensations for the malpositioned jaws were apparent in most cases and became worse as the skeletal malposition worsened.

In agreement with Miyajima's study, Alexander recently examined the longitudinal growth of Caucasian Class III individuals and found that incremental increase of anterior cranial base and position of maxilla relative to cranial base remain relatively constant throughout growth ${ }^{75}$. Slight but statistically insignificant decrease in midface growth was noted among these individuals. Increments of mandibular growth for these individual is slightly larger than the average reported by Proffit and the duration of mandibular growth also appear to last longer ${ }^{57}$. Again, there is a worsening of maxillo-mandibular relationship overtime along with compensatory dentoalveolar changes of maxillary incisor proclination and mandibular incisor retroclination.

In another study, Baccetti looked at the growth of Caucasian Class III individuals of differing skeletal maturations determined based on cervical vertebral maturation ${ }^{22}$. Significant growth changes of the mandible occurred until young adulthood with peak mandibular growth occurring between CVM stages 3 and 4 and smaller changes occurring until CVM 5 in some patients. Amount of mandibular growth for the examined individuals is larger compared to those of Class I individuals (control) for both male and females. An increase in the vertical dimension in the later stages of development was also noted. Similar change in sagittal and vertical dimension among Caucasian Class III individuals were also shown in a study by Reyes ${ }^{15}$. 


\section{TREATMENT OF CLASS III MALOCCLUSION}

There are several treatment options for patients with Class III skeletal pattern:

1. Non-extraction/camouflage

2. Extraction/camouflage

3. Functional or orthopedic appliance

4. Surgery

\section{Camouflage Treatment}

Camouflage treatment of Class III patients either via non-extraction or extraction method often involves proclining maxillary incisors and retroclining mandibular incisors to establish positive overjet. It is important to identify patients with severe skeletal discrepancy in which orthodontic treatment would not be successful. When pre-treatment dentoalveolar compensation has already occurred, further treatment is often limited. In patients with a moderate skeletal discrepancy, proclination of the upper incisors in isolation will be unstable and potentially traumatic to the occlusion and periodontium, so oftentimes lower incisor retroclination is required.

In many cases, extractions are recommended to treat the malocclusion, especially if crowding is present. One reason to extract teeth is to obtain space to eliminate crowding and align the remaining teeth within the arch. The second reason is to camouflage a moderate skeletal discrepancy when orthopedic correction is not possible. Extraction patterns may vary from extraction of lower first bicuspids only, extraction of upper second premolars and lower first premolars, or even a lower central incisor is sometimes recommended for mild skeletal discrepancies in an adult patient ${ }^{76}$. Extractions allow the orthodontist to reduce the amount of negative overjet and camouflage the skeletal discrepancy. For adolescent patients approaching the limits of Class III camouflage treatment, orthodontic camouflage should be deferred until the remaining skeletal growth has been expressed so that a more predictable treatment outcome can be achieved. 


\section{Functional and orthopedic appliances}

Many different functional and orthopedic appliances have been used in the correction for the Class III malocclusion throughout history. Examples include different types of bite positioners, chin cup, protraction facemask, and more recently orthopedic appliances with skeletally anchored components. The main goal for use of these orthopedic appliances is to correct the Class III jaw pattern at an early age, thus providing a more favorable growth environment for the jaws as the patient matures ${ }^{77}$. However, even when the jaw discrepancy is corrected at an early age, if the patient continues to grow in an unfavorable Class III pattern, surgery may still be needed later on. Turpin's study led him to advise early treatment ${ }^{78}$. He concluded that a more favorable outcome of early treatment could be accomplished when the patient had a convergent facial type, an anterior-posterior functional shift, symmetrical condylar growth, has remaining growth, a mild skeletal disharmony, provides good cooperation, no familial history of Class III facial type, and good facial esthetics. The absence of one or more of these factors could lead the orthodontist to conclude that early treatment may not be beneficial in preventing surgery of the Class III patient.

Commonly used bite positioners to correct Class III malocclusion include the Frankel-III, Bionator III, and reverse twin block appliances. These functional appliances primarily have a dentoalveolar effect on treatment of Class III malocclusion instead of orthopedic effect ${ }^{79}$. The Frankel III appliance is designed to counteract the muscle forces acting on the maxillary complex ${ }^{80}$. Baik evaluated the use of Frankel functional regulator III in growing Class III patients and found that correction of the malocclusion mainly came from backward and downward rotation of the mandible and lingual tipping of the lower incisors ${ }^{81}$. A study by Loh and Kerr found there were minimal skeletal changes with respect to the maxilla ${ }^{82}$. Petit and McNamara recommended the use of FR-3 for retention after protraction headgear therapy $^{83,84}$.

Garattini used a Bionator III appliance in his study and concluded the majority of results to be attributed to dentoalveolar changes ${ }^{85}$. Similar results are noted by Kidner and Seehra, with the use of a 
Class III Twin Block ${ }^{86,87}$. Use of these functional appliances often results in mesial migration and extrusion of maxillary molars and minimal change in lower molar position. These appliances also procline the upper incisors and retrocline the lower incisors. The end result is the counter-clockwise rotation of the occlusal plane with clockwise rotation of the chin, with no major effect on the skeletal growth of the mandible or maxilla ${ }^{57}$. Use of these functional appliances has largely fallen out of favor due to the fact that they do not produce major orthopedic effects. One functional appliance that has been found to have a skeletal effect is a removable maxillary and mandibular splint attached with Class III interarch elastics ${ }^{88,89}$. This appliance has been reported to have minor orthopedic effect in additional to dentoalveolar movement, and A point was noted to move forward slightly among subjects treated with the appliance.

Orthopedic appliances that are used to correct Class III malocclusion include chin cup, protraction facemask and skeletally anchored orthopedic appliances. Chin-cup appliance was at one time the treatment of choice in pubertal class III patient because the focus for treatment was on controlling mandibular prognathism. It was employed to treat excessive mandibular growth by retarding or redirecting growth of the mandible in a downward and backward direction ${ }^{90,91}$. However, long-term stability results of this treatment have been disappointing. Sugawara found no effect of the chin cup in the anteroposterior direction of the maxilla ${ }^{92}$. Further research showed that recovery growth of the mandible can take place if chin cup therapy is discontinued before the completion of the pubertal growth spurt $^{92-98}$. Furthermore, reports of use of potential development of temporomandibular joint symptoms resulting from use of chin-cup therapy further discourage the use of this type of treatment on Class III malocclusion $^{97,98}$.

Since two-thirds of Class III malocclusions present with maxillary retrognathism, and chin cup therapy had been met with limited success, clinicians and researchers treatment focused their treatment on protracting the maxilla ${ }^{8,23,64}$. The main appliance used today in the early correction of Class III patients is the maxillary protraction facemask appliance. It is currently accepted as the most appropriate treatment 
for patients with a retrusive maxilla during the mixed dentition stage. The facemask is a removable appliance that achieves its desired effect by using the forehead and the chin as anchorage. Heavy orthopedic force is applied bilaterally via hooking elastics in a down and forward direction from either a dentally anchored or skeletally anchored maxillary appliance to the bow of the facemask. Ideally the direction of force is applied through the center of resistance of the maxilla, which occurs between orbitale and the mesiobuccal cusp of the maxillary first molar ${ }^{23-25}$. The facemask is worn for about 12-14 hours a day.

To maximize the skeletal change when using protraction headgear, rapid palatal expansion (RPE) is also be used initially to facilitate loosening of circummaxillary sutures ${ }^{99}$. Since 1970 when Haas showed downward and forward maxillary displacement with the use of palatal expansion, many clinical studies have noted that the use of a palatal expander in conjunction with protraction headgear enhanced maxillary protraction ${ }^{100-103}$. Palatal expansion helps to disarticulate the maxilla and initiates cellular response in the suture, allowing a more positive reaction to protraction forces ${ }^{100}$. RME can expand a narrow maxilla, correct posterior crossbite, increase arch length, and serve to splint the maxillary dentition during protraction facemask ${ }^{104,105}$. Due to the disarticulation of the circummaxillary sutures, several investigators advocate RME even in the absence of max constriction ${ }^{101,106}$. A repetitive weekly protocol of alternate rapid maxillary expansion and constriction (Alt-RAMEC) has been proposed to disarticulate the circummaxillary sutures, without over$\operatorname{expansion}^{107}$.

The main goal of this facemask is to provide skeletal correction by limiting growth of the mandible and protraction of the deficient maxillary complex in a down and forward direction. Conventional protraction facemask therapy, with an indirect application of force to the sutures through tooth borne anchorage, causes both skeletal and dental changes in the maxilla and the mandible. Correction of the Class III malocclusion occurs as a result of forward and downward movement of the 
maxilla, downward and backward rotation of the mandible, labial tip of the max incisors, and lingual tip of the mandibular incisors ${ }^{103,108-115}$. This is accompanied by an increase in lower face height and a decrease in overbite ${ }^{103,109,115}$. Previous studies have shown that traditional tooth borne protraction facemask devices have a loss in anchorage ${ }^{103,116}$. Researchers have noted excessive forward movement and extrusion of maxillary molars, excessive proclination of maxillary incisors, retroclination of mandibular incisors and an increase in lower face height ${ }^{103,116,117}$.

Studies have also been done to evaluate the treatment outcomes of dentally supported protraction facemask on both short and long term basis. Most studies declare a high success rate ( $76 \%$ to $100 \%)$ when outcomes of treatment are evaluated on a short- term basis ${ }^{118-123}$. However, when evaluating longterm stability of treatment outcome for facemask, the result is more controversial. It was found that while majority of the patients who received facemask treatment maintained positive overjet during long-term evaluation period, a small portion of the patients outgrow the correction ${ }^{124}$. It was also noted that the original Class III growth pattern resumed for most patient even when they maintain positive overjet throughout growth and that maintenance of positive overjet is a result of dentoalveorlar changes ${ }^{125-128}$. Two articles found that with aggressive overcorrection at a skeletal level during facemask treatment tend to produce more favorable orthopedic correction results long-term ${ }^{125,128}$.

To obtain maximum skeletal changes and minimize undesirable dental effects, it would be reasonable to take advantage of stable skeletal anchorage to transfer the force directly to the circummaxillary sutures. In this regard, researchers have attempted to design an absolute anchorage system for maxillary protraction ${ }^{32}$. These newer treatment modalities include the use of intentionally ankylosed maxillary deciduous canines ${ }^{33}$, osseointegrated titanium implants ${ }^{34,35}$, onplants ${ }^{35}$, miniscrews ${ }^{36-}$ ${ }^{38}(58)$ and most recently miniplates ${ }^{32,39-46}$. Each implants system has strengths and weaknesses. Ankylosed deciduous teeth limit orthopedic treatment to only the early mixed dentition period ${ }^{33}$. Adolescents usually have a set of permanent dentition with no available site for implant placement ${ }^{34}$. Titanium miniplates have been successfully used for several orthodontic anchorage needs including 
intrusion of molars, correction of anterior open bite, distalizing mandibular molars ${ }^{129}$. Miniplates are becoming more popular as anchorage in orthodontics because of their demonstrated safe use for fractures and osteotomies, and because they can be placed apical to the tooth $\operatorname{roots}^{32}$. Sar describes a technique using miniplates at the lateral nasal wall that are hooked to a protraction facemask to obtain pure skeletal anchorage $^{48}$. This technique also has a high surgical invasiveness, and it does not include an RPE in the design. Recent clinical studies have demonstrated maxillary protraction with the use of miniplate and intermaxillary elastics ${ }^{43,45,46,130,131}$. In other clinical studies, titanium miniplates have been shown to have absolute anchorage when orthopedic forces have been applied with facemasks $32,39,40,42,46,49,132$

To minimize the surgical invasiveness of the pure bone anchored devices, Wilmes et al have introduced the hybrid hyrax, a tooth and bone anchored expander ${ }^{37,49}$. Two mini-implants are placed in the anterior palate and an expansion device is connected to the mini-implants and to the first molars. After expansion the patient undergoes facemask therapy with elastics attached to hooks on the hybrid hyrax. In his initial study, Wilmes found this device to be effective for expansion, and was thought to minimize mesial migration of the dentition when used in conjunction with protraction facemask ${ }^{37}$. Wilmes' study did not determine dental and molar contributions from the appliance, and it did not compare the hybrid hyrax results to a conventional tooth anchored facemask group ${ }^{37}$.

\section{Orthognathic Surgery}

The last treatment option for patients with Class III malocclusion is orthognathic surgery. Although this treatment alternative will lead to the most ideal relationship of the maxilla and mandible in severe malocclusions, it is also the most invasive and carries a financial burden. On the other hand, surgery may be the only viable option for cases with moderate or severe Class III anteroposterior skeletal discrepancies where a vertical or transverse skeletal disharmony is present ${ }^{57}$. Pre-surgical orthodontic treatment usually involves the provision of fixed appliances to align the maxillary and mandibular arches, so that they will coordinate when the skeletal bases have been properly positioned. This necessitates both alignment and decompensation of the axial inclination of the incisors. According to McIntyre, the 
maxillary incisors are retroclined and the mandibular incisors are proclined to approximately $109^{\circ}$ and $90^{\circ}$, respectively to the maxillary and mandibular planes ${ }^{76}$. A short period of orthodontic treatment (about 6 months) is often required following surgery to finish and detail the occlusion.

\section{TREATMENT TIMING FOR CLASS III MALOCCLUSION}

The timing of maxillary protraction therapy varies by treatment method. If timing is incorrect, it can drastically prolong treatment, decrease patient motivation, and subsequently affect the outcome of treatment. Proffit noted that correction of mandibular prognathism should take place before the age of 7 and correction of a maxillary deficiency via orthopedic means should take place before the age of $10^{57}$. Baccetti looked at how age effects treatment outcomes with a bonded RPE and facemask and found that a more significant forward movement of A point occurred in the early treatment group (6.8 years \pm 0.6 years) than the late treatment group (10.3 years \pm 1.0 year $)^{114,122}$. Both group showed a restriction in mandibular length, but the result was more noted in the early treatment group. He also found that a restriction of mandibular growth was seen in both groups with a more upward and forward direction of condylar growth $^{114,122}$. In the late treatment group, a more pronounced down and backward rotation of the mandible was seen with an increase of lower anterior facial height.

In agreement with Proffit and Bacetti, Fanchi's study on evaluating the influence of treatment timing on Class III patients showed that those patients treated in the late deciduous to early mixed dentition benefited more than those that received treatment in the late mixed dentition stage ${ }^{133}$. However, both groups did benefit and this correction came as a result of skeletal changes.

Takada's study showed similar results with facemask treatment of Japanese female children divided into prepubertal, mid-pubertal, and late pubertal groups ${ }^{134}$. There was a significant increase in maxillary length for the pre-pubertal and mid-pubertal groups, but results were not as significant in the late pubertal group. 
The timing of maxillary protraction therapy varies by treatment method. Effective convention rapid maxillary expansion and protraction facemask therapy remains limited to the deciduous or early mixed dentition ${ }^{119,122,133,135-137}$. Several investigators advocate treatment in young children, before eight years of age ${ }^{57,101}$. The latest research on miniplates with protraction facemask or intermaxillary elastics has shown success in the later mixed or permanent dentition phases ${ }^{45,138,139}$. But these treatment modalities must still be used before the onset of the pubertal growth spurt ${ }^{122,140}$. Research has shown there is a decreased maximum maillary skeletal advancement and increased dentoalveolar effects in patients past pubertal growth peak ${ }^{137}$. Surgical placement of most miniplates cannot be placed before canine eruption; therefor orthopedic traction on miniplates usually cannot be started before the age of ten ${ }^{45}$. One clinical study used a mentoplate design that allows placement of the miniplate subapical to the incisors, permitting therapy in patients as young as eight ${ }^{46}$. One advantage of treating patients in the later mixed or permanent dentition is that clinicians are able to keep the post-orthopedic period of facial growth until adulthood shorter, and decreases the risk of catch up growth of the mandible ${ }^{45}$.

For adolescent patients approaching the limits of Class III camouflage treatment, orthodontic camouflage should be deferred until the remaining skeletal growth has been expressed so that a more predictable treatment outcome can be achieved ${ }^{57}$. The goal of treatment in the early permanent dentition stage is to produce a Class I incisor relationship and to attempt to compensate for the underlying skeletal discrepancy. However, the clinician must be sure that skeletal growth will not negate the treatment outcome, and the clinician should determine the whether or not the patient has a severe skeletal discrepancy in which orthodontic treatment would not be successful.

The literature presents several studies or case reports that compare the results from bone anchored protraction facemask therapy to results from conventional tooth borne protraction facemask therapy ${ }^{39,41,48}$. To date no literature has been presented comparing the results of the hybrid hyrax bone anchored 
maxillary expansion and protraction to tooth anchored maxillary expansion and protraction. The purpose of this study is to compare results from tooth anchored protraction facemask and bone anchored protraction facemask, and quantify skeletal and dental contributions. 


\section{CHAPTER III: MATERIAL AND METHODOLOGY}

\section{SAMPLE DESCRIPTION}

The study group consisted of 40 patients who were treated by tooth anchored rapid maxillary expansion and protraction facemask or by bone anchored hybrid hyrax expansion and protraction facemask. The inclusion criteria for patient selection are as follows:

- No prior orthopedic or orthodontic treatment.

- No craniofacial syndromes.

- Class III malocclusion at the time of the initial observation (T1) as defined by patient having either one or more of the following characteristics:

- Anterior crossbite or edge-to-edge incisal relationship.

- Accentuated mesial step relationship of the deciduous second molar, or at least half cusp Angel Class III relationship of the permanent first molar.

- Wits appraisal smaller than -3 or ANB smaller than -2 .

- Lateral cephalograms of adequate quality available for each of the time points, where bony and soft tissue landmarks are identifiable.

A sample of 20 patients with Class III malocclusions in the mixed dentition that underwent an observation period before beginning any orthodontic treatment were obtained from files at West Virginia University. This control group of Class III malocclusions with no treatment represents six months of growth.

Pre-treatment and post-treatment lateral cephalograms from 20 patients with Class III malocclusions in the mixed dentition that were treated with RPE and conventional tooth anchored protraction facemask, were obtained from the files at West Virginia University. This patient sample is the 
same group of 20 patients as the control/growth group listed above. This group was closely matched for patient age and sex with the bone anchored treatment group below.

Pre-treatment and post-treatment lateral cephalograms from 20 patients with Class III malocclusions in the mixed dentition that were treated with bone anchored hybrid hyrax RPE and protraction facemask were obtained from Dr. Benedict Wilmes, University of Dusseldorf, Germany. Figure 1 shows the hybrid hyrax appliance design.

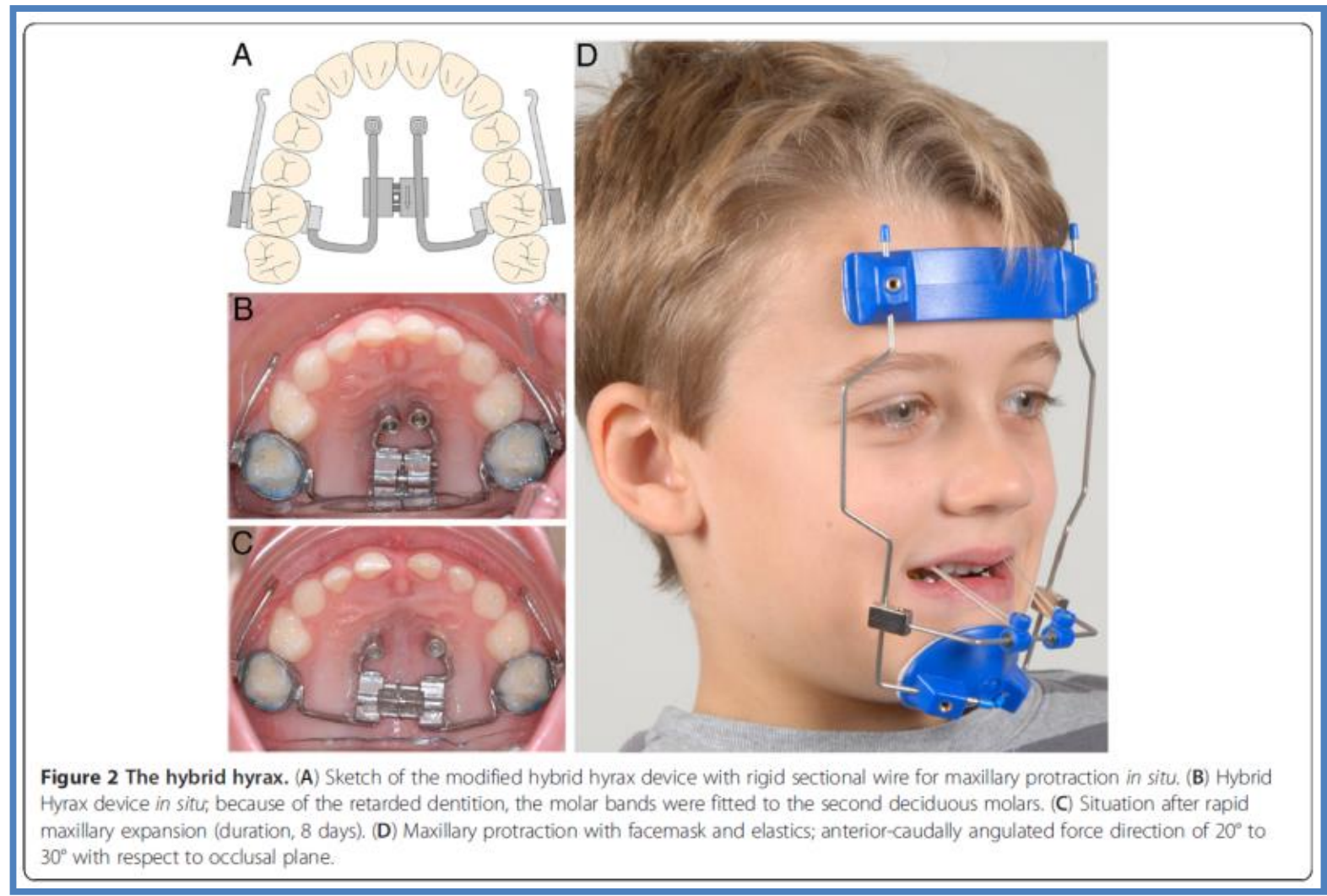

Figure 1. Hybrid Hyrax Appliance 


\section{IRB APPROVAL}

Please see Appendix A for IRB Exemption letter. 


\section{DATA ANALYSIS}

\section{Time Points}

Data from the following time points will be used:

\begin{tabular}{|l|l|}
\hline Symbol & Definition \\
\hline t0 & Growth subjects, no treatment of tooth anchored protraction facemask group \\
\hline $\mathrm{t} 1$ & $\begin{array}{l}\text { Tooth anchored protraction facemask subject's radiograph taken before } \\
\text { treatment, after a period of growth observation }\end{array}$ \\
\hline $\mathrm{t} 2$ & $\begin{array}{l}\text { Tooth anchored protraction facemask subject's radiograph taken at the end of } \\
\text { facemask therapy }\end{array}$ \\
\hline $\mathrm{T} 1$ & $\begin{array}{l}\text { Bone anchored protraction facemask subject's radiograph taken before } \\
\text { treatment }\end{array}$ \\
\hline T2 & $\begin{array}{l}\text { Bone anchored protraction facemask subject's radiograph taken at the end of } \\
\text { facemask therapy }\end{array}$ \\
\hline
\end{tabular}

Table 2. Symbols for the different time intervals.

Time $\mathrm{t} 1 \mathrm{-t} 0$ will give changes that are due to growth. Time $\mathrm{t} 2-\mathrm{t} 1$ will give treatment changes in the tooth anchored facemask group. Time T2- T1 will give treatment changes in the bone anchored facemask group. To determine the actual appliance effect, either from tooth anchored or bone anchored, the growth changes need to be subtracted from the treatment changes. Although pretreatment observation radiographs were taken for the tooth anchored group, and not the bone anchored group, it was assumed that the two groups would grow similarly during the same amount of treatment time since the two groups were matched for sex and age. Therefore, the growth changes were subtracted from both treatment groups to determine the effect of the appliance only. The calculation $(\mathrm{t} 2-\mathrm{t} 1)-(\mathrm{t} 1-\mathrm{t} 0)$ give the appliance effect of the tooth anchored facemask. The calculation $(\mathrm{T} 2-\mathrm{T} 1)-(\mathrm{t} 1-\mathrm{t} 0)$ gives the appliance effect of the bone anchored facemask.

\section{Radiographic Analysis}

Radiograph from each time point were collected. The lateral cephalograms from West Virginia University were film based. The lateral cephalograms from Dr. Wilmes were received as jpeg files. The jpegs were digitized and calibrated using Dolphin Imaging Software (Dolphin, Chatsworth, CA). Each image was printed at a 1:1 ratio with Epson Stylus Prof 3880 Printer (Long Beach, California) on quality 
photo paper (HP Premium Photo Paper). The radiographs were hand traced using a custom cephalometric analysis incorporating elements from Steiner, Wits, McNamara, Ricketts and Jarabak. Lateral cephalograms often present landmarks with right and left images; therefore the midpoints bisecting the two images were used. For this study, the variables were categorized into three groups: sagittal (linear, $\mathrm{mm}$ ), vertical (linear, $\mathrm{mm}, \%$ ), and angular, with a total of 37 variables. Sagittal and vertical linear measurements were recorded to the nearest $0.1 \mathrm{~mm}$ and/or 0.1 of a percentage. Angular measurements were reported to the nearest 0.1 degrees. Tracings were performed by one operator (NMD) using a $0.5 \mathrm{~mm}$ mechanical led pencil, 3M Unitek orthodontic protractor (Monrovia, CA), and 0.003 inch matte 3M Unitek cephalometric acetate tracing film (Monrovia, CA). Figure 2 and Table 3 desribe the skeletal and dental landmarks used in this study. Figure 3 and Table 4 describe the reference lines used in this study.

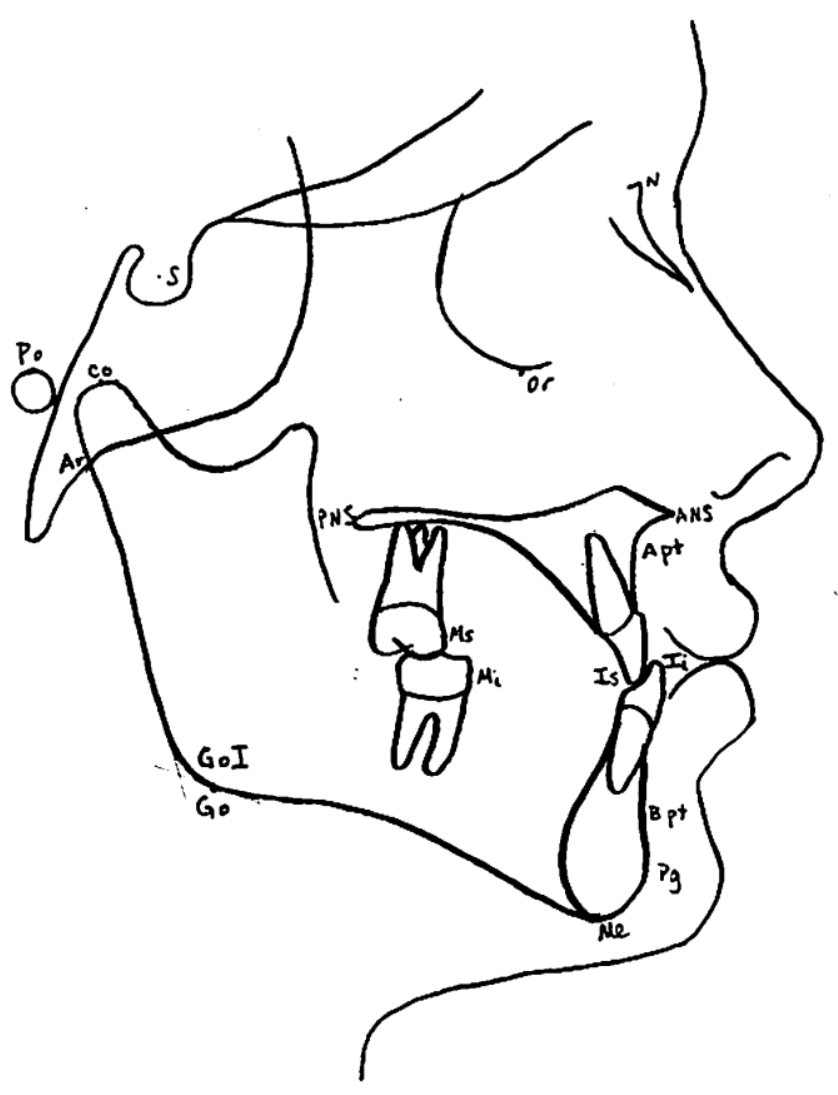

Figure 2. Skeletal and Dental Landmarks 


\begin{tabular}{|c|c|c|}
\hline Name & Symbol & Definition \\
\hline Sella & $\mathrm{S}$ & The center of the sella turcica \\
\hline Nasion & $\mathrm{N}$ & The most anterior point of the fronto-nasal suture \\
\hline Orbitale & Or & Lowest point on the inferior margin of the orbit \\
\hline Porion & Po & Uppermost point of bony external auditory canal \\
\hline Anterior nasal spine & ANS & The apex of the spina nasalis anterior \\
\hline Posterior nasal spine & PNS & $\begin{array}{l}\text { The most posterior point on contour of the palate in the } \\
\text { midsagittal plane }\end{array}$ \\
\hline Subspinale & A pt. & $\begin{array}{l}\text { The deepest point in the concavity of the anterior maxilla } \\
\text { between the ANS and the alveolar crest }\end{array}$ \\
\hline Supramentale & B pt. & $\begin{array}{l}\text { The deepest point in the concavity of the anterior mandible } \\
\text { between the alveolar crest and pogonion }\end{array}$ \\
\hline Pogonion & $\mathrm{Pg}$ & The most prominent point on the chin \\
\hline Menton & $\mathrm{Me}$ & The deepest point of the mandibular symphysis \\
\hline Gonion & Go & Most posterior inferior point on angle of mandible \\
\hline Gonial Intersection & GoI & Constructed point at junction of ramal and mandibular planes \\
\hline Articulare & $\mathrm{Ar}$ & $\begin{array}{l}\text { Intersection of posterior border of ramus and inferior border } \\
\text { of occipital bone }\end{array}$ \\
\hline Condylion & $\mathrm{Co}$ & Most superior point on head of condyle \\
\hline Maxillary incisor tip & Is & $\begin{array}{l}\text { The incisal point of the most prominent maxillary central } \\
\text { incisor }\end{array}$ \\
\hline Mandibular incisor tip & Ii & $\begin{array}{l}\text { The incisal point of the most prominent mandibular central } \\
\text { incisor }\end{array}$ \\
\hline Molar superius & Ms & $\begin{array}{l}\text { The mesial contact point of the maxillary primary second } \\
\text { molar or permanent first molar }\end{array}$ \\
\hline $\begin{array}{l}\text { Molar superius mesial } \\
\text { cusp }\end{array}$ & Msc & $\begin{array}{l}\text { The mesio-buccal cusp tip of the maxillary second primary } \\
\text { molar or first permanent molar }\end{array}$ \\
\hline Molar inferius & $\mathrm{Mi}$ & $\begin{array}{l}\text { The mesial contact point of the mandibular primary second } \\
\text { molar or permanent first molar }\end{array}$ \\
\hline $\begin{array}{l}\text { Molar inferius mesial } \\
\text { cusp }\end{array}$ & Mic & $\begin{array}{l}\text { The mesial-buccal cusp tip of the mandibular primary second } \\
\text { molar or permanent first molar }\end{array}$ \\
\hline
\end{tabular}

Table 3. Definition of Skeletal and Dental Landmarks 


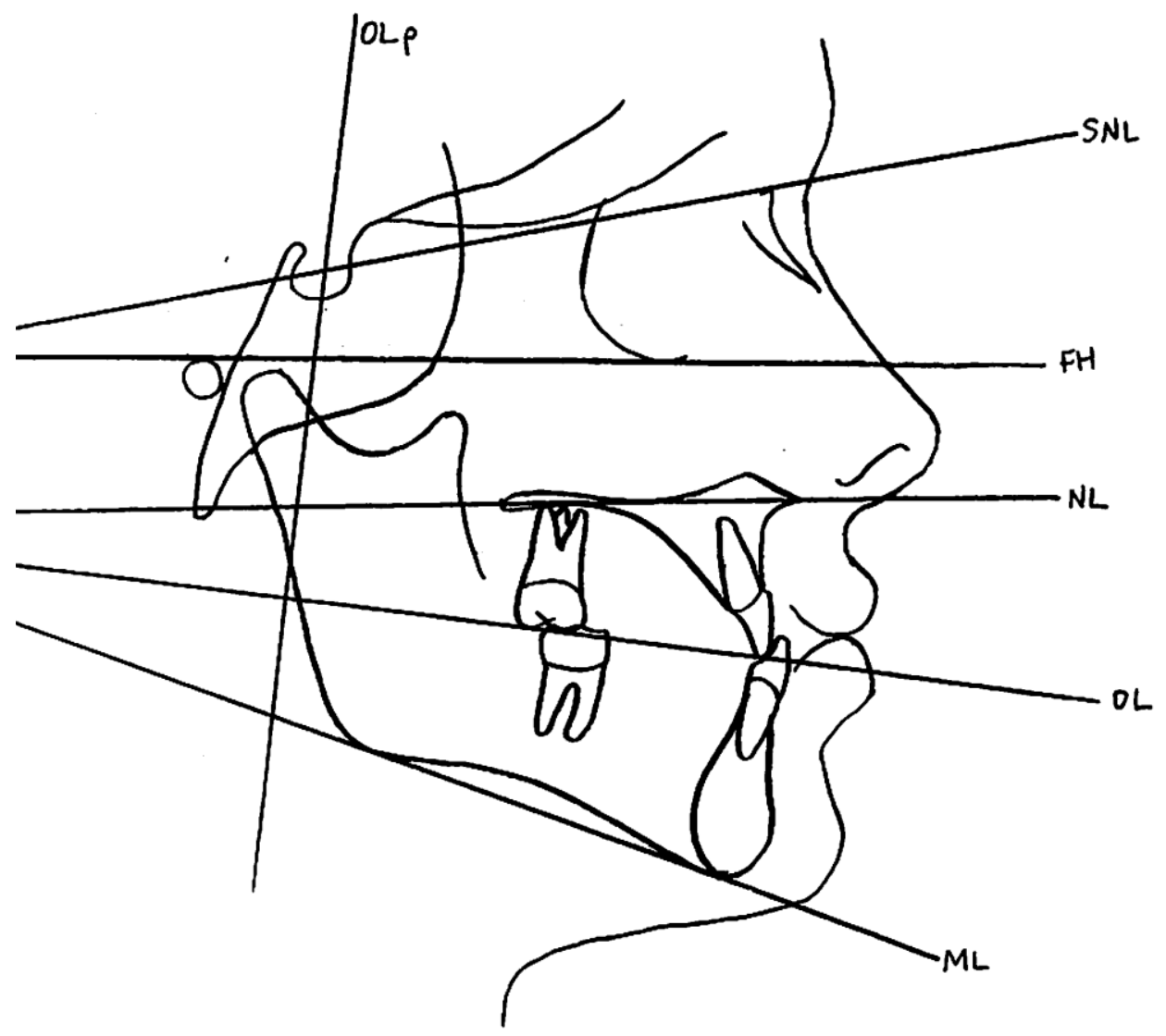

Figure 3. Reference Lines

\begin{tabular}{|l|l|l|}
\hline Name & Symbol & Definition \\
\hline Sella-Nasion plane & SNL & Reference line joining sella and nasion \\
\hline Frankfort Horizontal & FH & Reference line joining porion and orbitale \\
\hline Maxillary plane & NL & $\begin{array}{l}\text { Reference line joining anterior nasal spine and posterior } \\
\text { nasal spine }\end{array}$ \\
\hline Occlusal plane & OL & $\begin{array}{l}\text { Reference line joining maxillary incisal edge and the } \\
\text { molar superious mesial cusp tip }\end{array}$ \\
\hline Mandibular plane & ML & Reference line joining menton and gonion \\
\hline $\begin{array}{l}\text { Occlusal plane } \\
\text { perpendicular }\end{array}$ & OLp & $\begin{array}{l}\text { Reference line produced by dropping a perpendicular line } \\
\text { from sella to the occlusal plane }\end{array}$ \\
\hline
\end{tabular}

Table 4. Definition of Reference Lines 


\section{Sagittal Measurements}

A total of 13 sagittal variables were evaluated, 7 skeletal and 6 dental, as shown in Table 5. A reference grid based on the occlusal line (OL) and occlusal line perpendicular (OLp) were created, as shown in Figure 4. Skeletal changes in the sagittal plane were measured utilizing the reference grid, as well as cephalometric variables that are used in WITS and McNamara analysis. Dental changes were measured utilizing the reference grid.

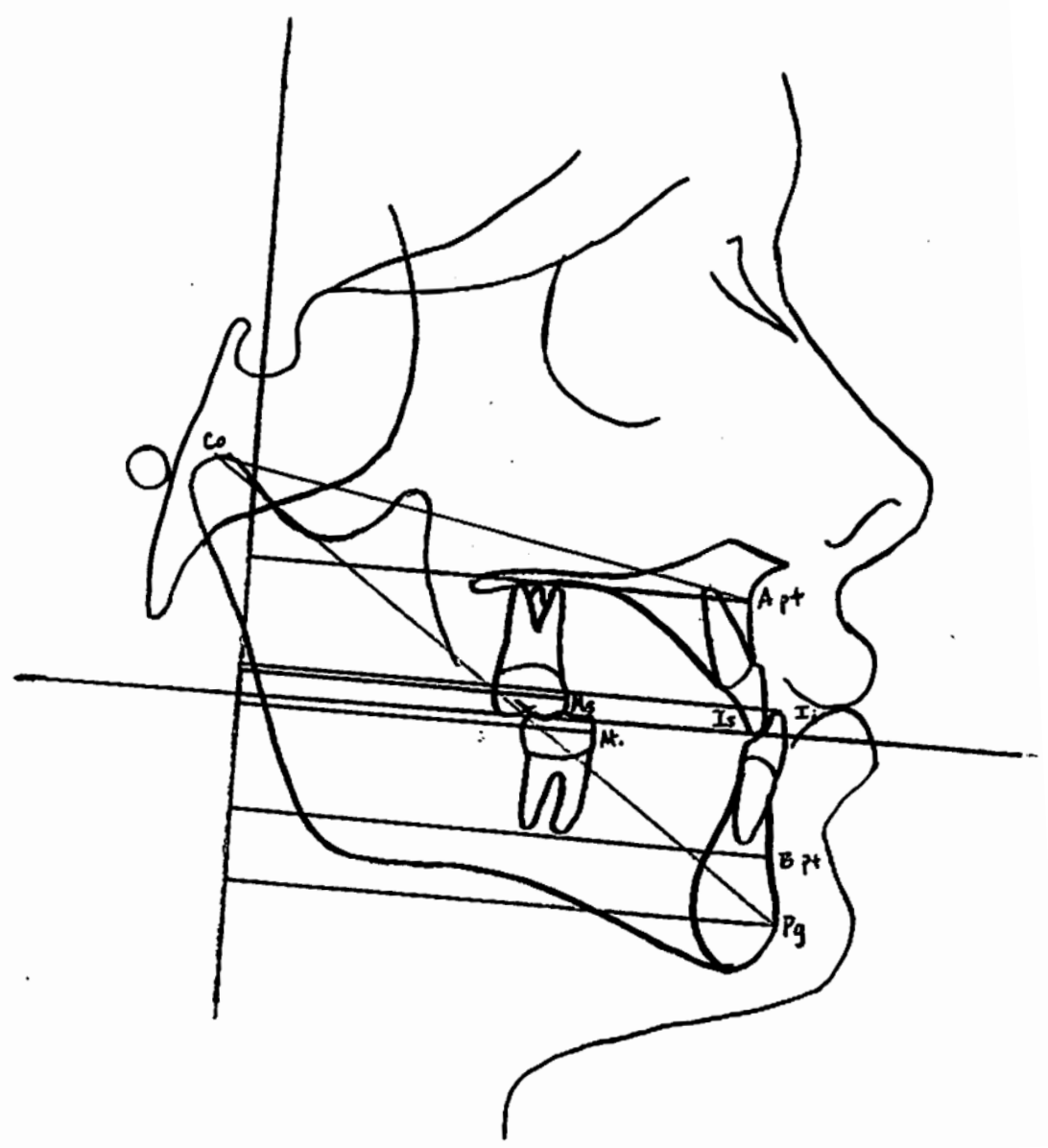

Figure 4. Reference Grid and Landmarks used in Sagittal Measurements 


\begin{tabular}{|c|c|}
\hline Variable (mm) & Definition \\
\hline \multicolumn{2}{|c|}{ Skeletal measuring points: } \\
\hline 1. OLp - A pt. & Position of maxillary base \\
\hline 2. OLp-B pt. & Position of mandibular base \\
\hline 3. OLp $-\mathrm{Pg}$ & Position of mandibular chin \\
\hline 4. Wits & OLp-A minus Olp-B, Maxillary base position relative to mandibular base \\
\hline 5. $\mathrm{Co}-\mathrm{A} \mathrm{pt}$ & Effective maxillary length \\
\hline 6. $\mathrm{Co}-\mathrm{Pg}$ & Effective mandibular length \\
\hline 7. $\mathrm{Co}-\mathrm{Pg}-\mathrm{Co}-\mathrm{A}$ & Difference between effective maxillary and mandibular length \\
\hline \multicolumn{2}{|l|}{ Dental measuring points: } \\
\hline 8. OLp - Is & Position of maxillary central incisor \\
\hline 9. OLp-Ii & Position of mandibular central incisor \\
\hline 10. Overjet & $\begin{array}{l}\text { OLp-Is minus OLp-Ii, Distance between maxillary and mandibular } \\
\text { incisor tip }\end{array}$ \\
\hline 11. OLp-Ms) & Position of maxillary second primary or first permanent molar \\
\hline 12. OLp - Mi & Position of mandibular second primary or first permanent molar \\
\hline 13. Molar Relationship & $\begin{array}{l}\text { OLp-Ms minus OLp-Mi, Distance between maxillary first permanent } \\
\text { molar and mandibular first permanent molar }\end{array}$ \\
\hline
\end{tabular}

Table 5. Sagittal Variables

\section{Vertical Measurements}

A total of 11 vertical variables were evaluated, 6 skeletal and 5 dental, as shown in Table 6 . Skeletal changes in the vertical plane were measured utilizing cephalometric variables that are used in Tweed analysis. A point vertical was measured from a constructed line parallel to OL through Sella, so that it would have a positive value, as shown in Figure 5. 


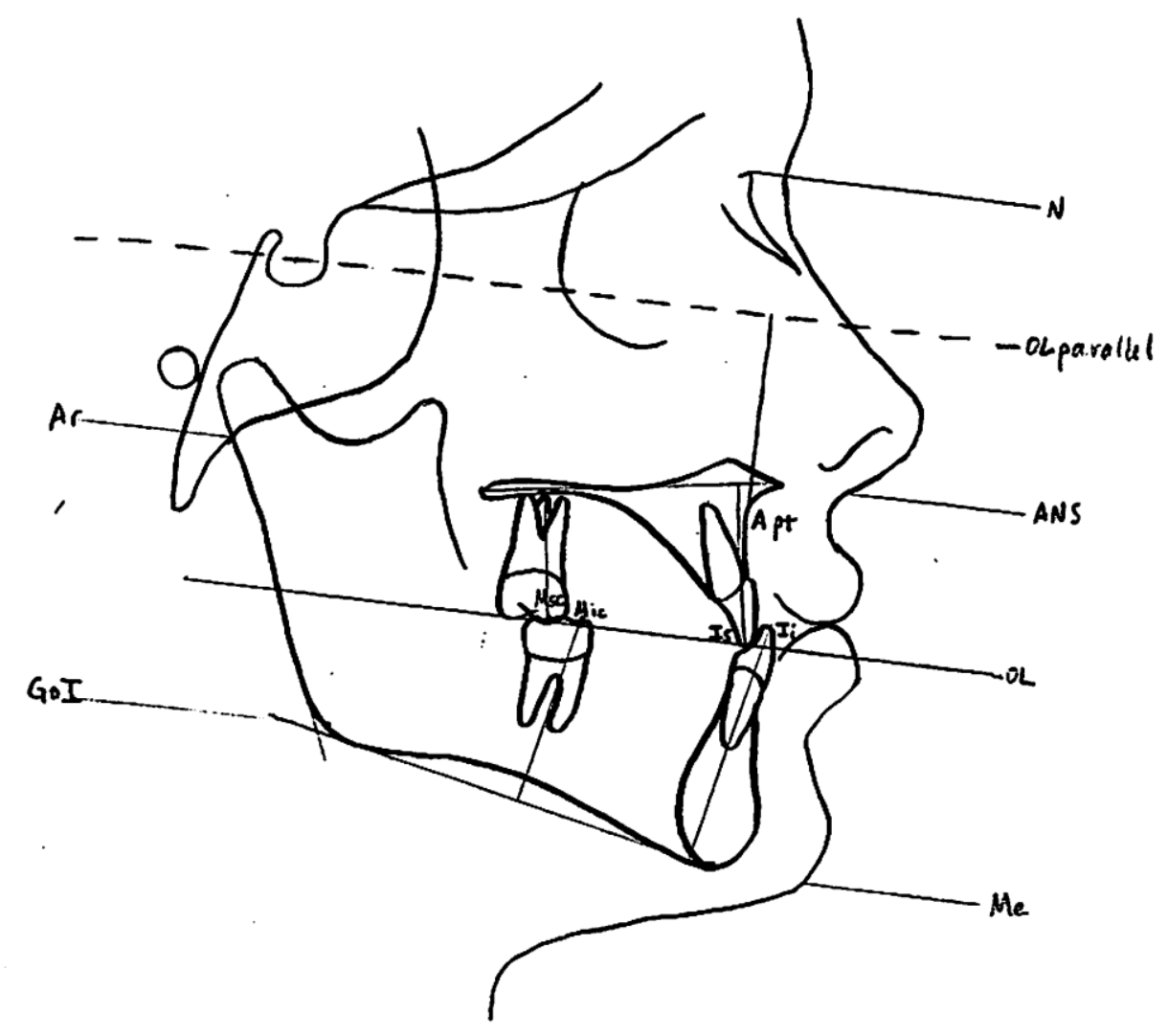

Figure 5. Landmarks used in Vertical Measurements

\begin{tabular}{|l|l|}
\hline Variable (mm or \%) & Definition \\
\hline Skeletal measuring points: & \\
\hline 14. OLparallel - A pt & Maxillary vertical positioning \\
\hline 15. N-Me & Total facial height \\
\hline 16. ANS - Me & Lower anterior facial height \\
\hline 17. Ar $-\mathrm{GoI}$ & Posterior facial height \\
\hline 18. ANS-Me / N-Me & Ratio between lower facial height and total facial height \\
\hline 19. Ar-GoI / ANS-Me & Ratio between posterior facial height and anterior facial height \\
\hline Dental measuring points: & \\
\hline 20. Is $-\mathrm{NL}$ & Position of maxillary central incisor relative to maxillary plane \\
\hline 21. Ii $-\mathrm{ML}$ & Position of mandibular central incisor relative to mandibular plane \\
\hline 22. Overbite & Is minus Ii, Overlap between maxillary and mandibular incisors \\
\hline 23. Msc - NL & $\begin{array}{l}\text { Position of maxillary primary second or permanent first molar relative to } \\
\text { maxillary plane }\end{array}$ \\
\hline 24. Mic - ML & $\begin{array}{l}\text { Position of mandibular primary second or permanent first molar relative } \\
\text { to mandibular plane }\end{array}$ \\
\hline
\end{tabular}

Table 6. Vertical Variables 


\section{Angular Measurements}

A total of 13 angular variables were evaluated, 11 skeletal and 2 dental, as shown in Table 7.

Angular measurements were based on cephalometric elements from Steiner, Jarabak, and Tweed analysis. Figure 6 illustrates angular measurements.

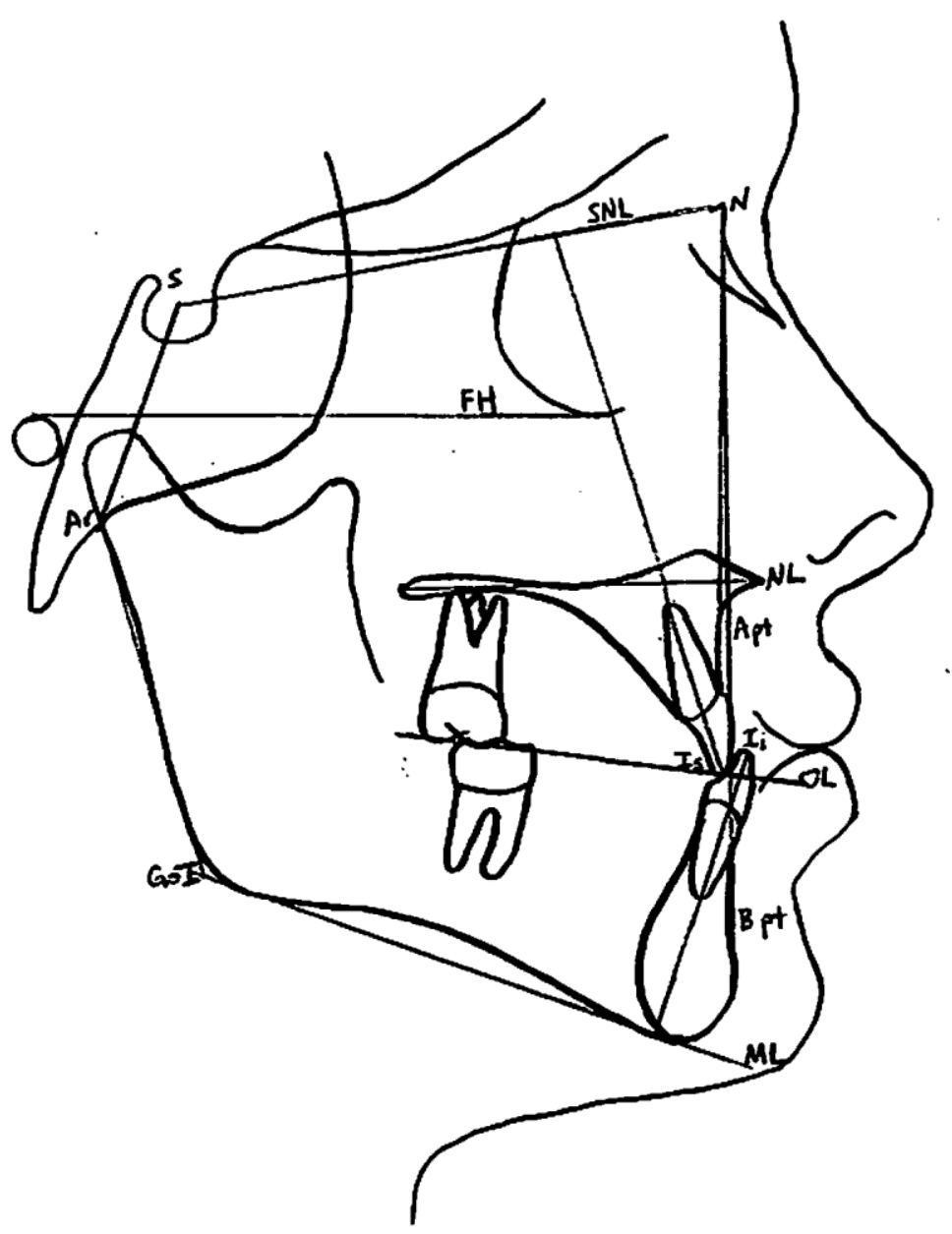

Figure 6. Landmarks used in Angular Measurements 


\begin{tabular}{|l|l|}
\hline Variable $\left({ }^{\circ}\right)$ & Definition \\
\hline Skeletal measuring points: & \\
\hline 25. SNA & Maxillary base relative to SNL \\
\hline 26. SNB & Mandibular base relative to SNL \\
\hline 27. ANB & SNA minus SNB \\
\hline 28. $\mathrm{N}-\mathrm{S}-\mathrm{Ar}$ & Saddle angle \\
\hline 29. $\mathrm{S}-\mathrm{Ar}-\mathrm{GoI}$ & Articulare angle \\
\hline 30. $\mathrm{Ar}-\mathrm{GoI}-\mathrm{Me}$ & Gonial angle \\
\hline 31. Jarabak sum of the angles & SN-Ar + SAr-ARGoI + Ar-GoI-Me \\
\hline 32. SNL $-\mathrm{ML}$ & Mandibular plane angle relative to SNL \\
\hline 33. $\mathrm{FH}-\mathrm{ML}$ & Mandibular plane relative to Frankfort Horizontal \\
\hline 34. SNL - OL & Occlusal plane angle relative to SNL \\
\hline 35. SNL - NL & Maxillary plane angle relative to SNL \\
\hline Dental measuring points: & \\
\hline 36. Is $-\mathrm{SNL}$ & Maxillary incisor angle relative to SNL \\
\hline 37. Ii $-\mathrm{ML}$ & Mandibular incisor angle relative to ML \\
\hline
\end{tabular}

Table 7. Angular Variables

\section{METHOD ERROR}

The reliability of this study is tested by investigating the error in superimposing, locating and tracing, and measuring the lateral cephalograms. To validate reproducibility of the measurements, 10 randomly selected lateral cephalograms were retraced and remeasured two weeks after the initial tracing. A matched-pairs reliability test was used to statistically analyze each measurement to establish a coefficient of reliability to determine the degree of reliability of the study. For all cephalometric variables, differences between the measurements recorded at the first tracing and the second tracing session were compared. The correlation results presented in Table 8 demonstrate how closely each variable from the first tracing session were replicated during the second tracing session. A value close to one indicates a strong positive correlation, and reliable data. The correlations ranged from 0.97 to 0.99 . The method of cephalometric analysis used in this study was determined to be reliable and repeatable. 


\begin{tabular}{|c|c|c|c|c|c|c|}
\hline \multirow[t]{2}{*}{ Variable Name } & \multicolumn{3}{|c|}{ Tooth anchored protraction facemask } & \multicolumn{3}{|c|}{ Bone anchored protraction facemask } \\
\hline & Mean 1 & Mean 2 & $\begin{array}{l}\text { Reliability } \\
\text { Coefficient }\end{array}$ & Mean 1 & Mean 2 & $\begin{array}{l}\text { Reliability } \\
\text { Coefficient }\end{array}$ \\
\hline \multicolumn{7}{|l|}{ Skeletal } \\
\hline 1. OLp-A pt. & 0.76 & 0.76 & 0.99 & 0.71 & 0.71 & 0.99 \\
\hline 2. OLp-B pt. & -2.43 & -2.39 & 0.97 & -1.43 & -1.45 & 0.98 \\
\hline 3. OLp - Pg & -2.20 & -2.19 & 0.99 & -1.24 & -1.24 & 0.99 \\
\hline 4. Wits & 2.33 & 2.33 & 0.99 & 2.29 & 2.28 & 0.98 \\
\hline 5. $\mathrm{Co}-\mathrm{A}$ & 0.06 & 0.07 & 0.98 & 0.85 & 0.85 & 0.99 \\
\hline 6. $\mathrm{Co}-\mathrm{Pg}$ & 0.62 & 0.62 & 0.99 & 1.00 & 1.00 & 0.99 \\
\hline 7. $\mathrm{Co}-\mathrm{Pg}-\mathrm{Co}-\mathrm{A}$ & -0.68 & -0.67 & 0.99 & 0.14 & 0.14 & 0.99 \\
\hline \multicolumn{7}{|l|}{ Dental } \\
\hline 8. OLp-Is & 2.26 & 2.26 & 0.99 & 0.82 & 0.80 & 0.98 \\
\hline 9. OLp-Ii & -3.62 & -3.60 & 0.98 & -2.53 & -2.53 & 0.99 \\
\hline 10. Overjet & 5.88 & 5.88 & 0.99 & 3.35 & 3.34 & 0.99 \\
\hline 11. OLp -Ms & 1.44 & 1.44 & 0.99 & 1.13 & 1.13 & 0.99 \\
\hline 12. OLp-Mi & -1.39 & -1.38 & 0.99 & 0.16 & 0.18 & 0.98 \\
\hline 13. Molar Relationship & 2.72 & 2.72 & 0.99 & 1.16 & 1.16 & 0.99 \\
\hline \multicolumn{7}{|l|}{ Skeletal } \\
\hline 14. OLparallel - A pt & 1.23 & 1.25 & 0.98 & -0.48 & -0.48 & 0.99 \\
\hline 15. $\mathrm{N}-\mathrm{Me}$ & 3.35 & 3.35 & 0.99 & 2.40 & 2.41 & 0.99 \\
\hline 16. ANS - Me & 2.09 & 2.09 & 0.99 & 1.66 & 1.66 & 0.99 \\
\hline \begin{tabular}{|l} 
17. $\mathrm{Ar}-\mathrm{GoI}$ \\
\end{tabular} & -0.30 & -0.25 & 0.97 & 0.64 & 0.62 & 0.98 \\
\hline 18. ANS $-\mathrm{Me} / \mathrm{N}-\mathrm{Me}$ & 0.003 & 0.003 & 0.99 & 0.001 & 0.001 & 0.99 \\
\hline 19. $\mathrm{Ar}-\mathrm{GoI} / \mathrm{ANS}-\mathrm{Me}$ & -0.008 & -0.008 & 0.99 & 0.001 & 0.001 & 0.99 \\
\hline \multicolumn{7}{|l|}{ Dental } \\
\hline 20. Is $-\mathrm{NL}$ & -0.55 & -0.55 & 0.99 & 1.30 & 1.30 & 0.99 \\
\hline 21. Ii-ML & 0.09 & 0.09 & 0.99 & 0.57 & 0.57 & 0.99 \\
\hline 22. Overbite & -1.59 & -1.59 & 0.99 & -0.46 & -0.45 & 0.98 \\
\hline 23. Msc $-\mathrm{NL}$ & 0.85 & 0.85 & 0.99 & 1.06 & 1.06 & 0.99 \\
\hline 24. Mic - ML & 0.71 & 0.71 & 0.99 & 0.88 & 0.89 & 0.98 \\
\hline \multicolumn{7}{|l|}{ Skeletal } \\
\hline 25. SNA & 0.41 & 0.43 & 0.98 & 1.29 & 1.29 & 0.99 \\
\hline 26. SNB & -2.34 & -2.34 & 0.99 & -1.34 & -1.34 & 0.99 \\
\hline 27. ANB & 2.75 & 2.75 & 0.99 & 2.63 & 2.62 & 0.99 \\
\hline 28. $\mathrm{N}-\mathrm{S}-\mathrm{Ar}$ & 0.07 & 0.06 & 0.98 & 1.24 & 1.27 & 0.98 \\
\hline 29. $\mathrm{S}-\mathrm{Ar}-\mathrm{GoI}$ & 4.34 & 4.37 & 0.98 & -0.14 & -0.14 & 0.99 \\
\hline 30. $\mathrm{Ar}-\mathrm{GoI}-\mathrm{Me}$ & -1.75 & -1.75 & 0.99 & -2.06 & -2.06 & 0.99 \\
\hline 31. Jarabak & 2.65 & 2.61 & 0.97 & -1.01 & -1.02 & 0.98 \\
\hline 32. SNL - ML & 2.94 & 2.96 & 0.98 & 0.74 & 0.74 & 0.99 \\
\hline 33. $\mathrm{FH}-\mathrm{ML}$ & 2.64 & 2.64 & 0.99 & 0.66 & 0.66 & 0.99 \\
\hline 34. $\mathrm{SNL}-\mathrm{OL}$ & -1.84 & -1.84 & 0.99 & -0.61 & -0.61 & 0.99 \\
\hline 35. SNL $-\mathrm{NL}$ & 0.77 & 0.76 & 0.99 & 0.84 & 0.84 & 0.99 \\
\hline \multicolumn{7}{|l|}{ Dental } \\
\hline 36. Is - SNL & -0.21 & -0.21 & 0.99 & -4.52 & -4.54 & 0.98 \\
\hline 37. Ii-ML & -4.61 & -4.61 & 0.99 & -1.08 & -1.08 & 0.99 \\
\hline
\end{tabular}

Table 8. Correlation Coefficients for Sagittal, Vertical, and Angular Measurements 


\section{STATISTICAL ANALYSIS}

The statistical analysis was carried about by the statistician (E.G.) utilizing the JMP version 90.9 SAS Software (Cary, NC). The appliance effect of the two groups of patients (tooth anchored and bone anchored) were compared to each other with respect to their cephalometric measurement means. An Analysis of Variance (ANOVA) was used to determine significant differences between the mean appliance effects for each variable for the tooth anchored and bone anchored protraction facemask groups. Mean, standard deviation, minimum and maximum measurement for changes of each cephalometric variable were also calculated for each group of patients. The significance level for all ANOVA analysis was set at $\mathrm{p}<0.05$. 


\section{CHAPTER IV: RESULTS}

Age and Sex Distribution

\begin{tabular}{|l|l|l|l|l|l|}
\hline & \multicolumn{2}{l|}{$\begin{array}{l}\text { Control and Tooth anchored } \\
\text { protraction facemask }\end{array}$} & \multicolumn{2}{l|}{$\begin{array}{l}\text { Bone anchored } \\
\text { protraction facemask }\end{array}$} \\
\hline & t0 & t1 & t2 & T1 & T2 \\
\hline Mean & 8.95 & 9.76 & 10.52 & 9.55 & 10.4 \\
\hline S.D. & 1.77 & 1.63 & 1.66 & 1.19 & 1.27 \\
\hline Min & 6.1 & 6.9 & 7.11 & 8 & 9 \\
\hline Max & 12.7 & 13.2 & 14.1 & 12 & 13 \\
\hline
\end{tabular}

Table 9. Age and Sex Distribution of Tooth Anchored Protraction Facemask and Bone Anchored Protraction Facemask Groups

The pretreatment (t1) tooth anchored group were matched for age and sex to the pretreatment (T1) bone anchored group. There were 8 males and 12 females in each group. 


\begin{tabular}{|c|c|c|c|c|c|c|}
\hline \multirow[t]{2}{*}{ Variable Name } & \multicolumn{2}{|c|}{$\begin{array}{l}\text { Tooth anchored } \\
\text { protraction facemask }\end{array}$} & \multicolumn{2}{|c|}{$\begin{array}{l}\text { Bone anchored protraction } \\
\text { facemask }\end{array}$} & \multicolumn{2}{|l|}{ ANOVA } \\
\hline & Mean t1 & SD & Mean T1 & SD & $\mathrm{p}$-value & Significance \\
\hline \multicolumn{7}{|l|}{ SAGITTAL $(\mathrm{mm})$} \\
\hline \multicolumn{7}{|l|}{ Skeletal } \\
\hline 1. OLp-A pt. & 70.90 & 4.06 & 66.74 & 3.93 & 0.002 & $* *$ \\
\hline 2. OLp-B pt. & 79.94 & 5.17 & 71.85 & 5.13 & 0.0001 & $* * *$ \\
\hline 3. OLp - Pg & 81.43 & 5.75 & 73.94 & 4.69 & 0.0001 & $* * *$ \\
\hline 4. Wits & -8.59 & 3.23 & -5.11 & 2.57 & 0.0006 & $* * *$ \\
\hline 5. $\mathrm{Co}-\mathrm{A}$ & 78.89 & 3.36 & 73.02 & 4.08 & 0.0001 & $* * *$ \\
\hline 6. $\mathrm{Co}-\mathrm{Pg}$ & 107.32 & 3.57 & 97.19 & 5.50 & 0.0001 & $* * *$ \\
\hline 7. $\mathrm{Co}-\mathrm{Pg}-\mathrm{Co}-\mathrm{A}$ & 28.42 & 2.71 & 24.17 & 3.88 & 0.0003 & $* * *$ \\
\hline \multicolumn{7}{|l|}{ Dental } \\
\hline 8. OLp - Is & 78.64 & 5.12 & 70.27 & 4.67 & 0.0001 & $* * *$ \\
\hline 9. OLp - Ii & 80.71 & 5.15 & 71.13 & 4.67 & 0.0001 & $* * *$ \\
\hline 10. Overjet & -2.06 & 0.94 & -0.86 & 2.30 & 0.037 & $*$ \\
\hline 11. OLp-Ms & 51.35 & 4.68 & 44.45 & 3.17 & 0.0001 & $* * *$ \\
\hline 12. OLp-Mi & 54.75 & 6.02 & 47.51 & 4.19 & 0.0001 & $* * *$ \\
\hline 13. Molar Relationship & -3.35 & 2.63 & -3.33 & 1.64 & 0.98 & N.S. \\
\hline \multicolumn{7}{|l|}{ VERTICAL $(\mathrm{mm} / \%)$} \\
\hline \multicolumn{7}{|l|}{ Skeletal } \\
\hline 14. OLparallel - A pt & 32.78 & 5.84 & 30.14 & 5.42 & 0.14 & N.S. \\
\hline 15. $\mathrm{N}-\mathrm{Me}$ & 110.21 & 4.54 & 100.45 & 5.97 & 0.0001 & $* * *$ \\
\hline 16. ANS - Me & 61.62 & 3.05 & 57.93 & 5.15 & 0.009 & $* *$ \\
\hline 17. $\mathrm{Ar}-\mathrm{GoI}$ & 38.46 & 4.00 & 35.16 & 4.30 & 0.016 & $*$ \\
\hline 18. $\mathrm{ANS}-\mathrm{Me} / \mathrm{N}-\mathrm{Me}$ & 0.55 & 0.01 & 0.57 & 0.02 & 0.025 & $*$ \\
\hline 19. $\mathrm{Ar}-\mathrm{GoI} / \mathrm{ANS}-\mathrm{Me}$ & 0.62 & 0.06 & 0.61 & 0.07 & 0.56 & N.S. \\
\hline \multicolumn{7}{|l|}{ Dental } \\
\hline 20. Is - NL & 26.80 & 2.72 & 22.41 & 3.68 & 0.0001 & $* * *$ \\
\hline 21. Ii-ML & 39.86 & 2.54 & 34.82 & 3.44 & 0.0001 & $* * *$ \\
\hline 22. Overbite & 3.45 & 2.46 & 1.56 & 2.18 & 0.014 & $*$ \\
\hline 23. $\mathrm{Msc}-\mathrm{NL}$ & 20.25 & 1.60 & 17.01 & 3.00 & 0.0001 & $* * *$ \\
\hline 24. Mic-ML & 29.80 & 1.30 & 26.50 & 2.06 & 0.0001 & $* * *$ \\
\hline \multicolumn{7}{|l|}{ ANGULAR $\left({ }^{\circ}\right)$} \\
\hline \multicolumn{7}{|l|}{ Skeletal } \\
\hline 25. SNA & 82.14 & 2.96 & 80.28 & 4.74 & 0.14 & N.S. \\
\hline 26. SNB & 82.56 & 2.87 & 81.20 & 4.17 & 0.23 & N.S. \\
\hline 27. ANB & -0.42 & 2.10 & -0.91 & 2.27 & 0.48 & N.S. \\
\hline 28. $\mathrm{SN}-\mathrm{Ar}$ & 122.60 & 5.42 & 118.69 & 5.59 & 0.03 & $*$ \\
\hline 29. $\mathrm{SAr}-\mathrm{ArGoI}$ & 144.61 & 4.51 & 143.62 & 5.86 & 0.55 & N.S. \\
\hline 30. $\mathrm{Ar}-\mathrm{GoI}-\mathrm{Me}$ & 127.20 & 8.51 & 132.28 & 7.01 & 0.046 & $*$ \\
\hline 31. Jarabak & 394.42 & 7.22 & 394.65 & 7.27 & 0.91 & N.S. \\
\hline 32. $\mathrm{SNL}-\mathrm{ML}$ & 33.42 & 4.77 & 32.62 & 6.06 & 0.64 & N.S. \\
\hline 33. FH - ML & 27.22 & 4.57 & 25.60 & 5.19 & 0.30 & N.S. \\
\hline 34. SNL-OL & 20.79 & 5.20 & 18.14 & 5.88 & 0.13 & N.S. \\
\hline 35. SNL-NL & 8.21 & 3.34 & 6.44 & 3.06 & 0.08 & N.S. \\
\hline \multicolumn{7}{|l|}{ Dental } \\
\hline 36. Is - SNL & 107.47 & 8.65 & 103.19 & 8.22 & 0.11 & N.S. \\
\hline 37. $\mathrm{Ii}-\mathrm{ML}$ & 90.35 & 9.55 & 84.75 & 3.47 & 0.018 & $*$ \\
\hline
\end{tabular}

\section{Table 10. Comparison of Craniofacial Morphology Before Treatment}

$\mathrm{NS}=$ not significantly different

$*$ = significantly different at $\mathrm{p}<0.05$

$* *=$ significantly different at $\mathrm{p}<0.01$

$* * *=$ significantly different at $\mathrm{p}<0.001$ 


\begin{tabular}{|c|c|c|c|c|c|c|c|c|c|}
\hline Variables $(\mathrm{mm})$ & t0 & & & & $\mathrm{t} 1$ & & & & $\mathrm{t} 1-\mathrm{t} 0$ \\
\hline Sagittal & Min & Max & Mean & S. D. & Min & Max & Mean & S. D. & $\begin{array}{l}\text { Mean } \\
\text { Difference }\end{array}$ \\
\hline Skeletal & & & & & & & & & \\
\hline OLp - A pt. & 62.7 & 77.3 & 70.07 & 3.89 & 63.1 & 78.3 & 70.9 & 4.06 & 0.83 \\
\hline OLp-B pt. & 71.3 & 86.1 & 78.9 & 5.06 & 71.9 & 86.7 & 79.94 & 5.17 & 1.04 \\
\hline OLp $-\mathrm{Pg}$ & 72 & 89.1 & 80.32 & 5.70 & 72.5 & 90.9 & 81.44 & 5.76 & 1.12 \\
\hline Wits & -14.0 & -2.6 & -8.88 & 3.23 & -14.2 & -3 & -8.60 & 3.24 & 0.28 \\
\hline $\mathrm{Co}-\mathrm{A}$ & 69.7 & 81.9 & 77.2 & 3.26 & 70.8 & 84.8 & 78.89 & 3.36 & 1.69 \\
\hline $\mathrm{Co}-\mathrm{Pg}$ & 90.1 & 113.2 & 104.93 & 4.62 & 98.3 & 115.5 & 107.32 & 3.57 & 2.39 \\
\hline $\mathrm{Co}-\mathrm{Pg}-\mathrm{Co}-\mathrm{A}$ & 20.4 & 31.3 & 27.72 & 3.03 & 22.3 & 33.3 & 28.43 & 2.72 & 0.71 \\
\hline Dental & & & & & & & & & \\
\hline OLp - Is & 65.0 & 84.1 & 77.26 & 4.87 & 66.2 & 87.4 & 78.64 & 5.13 & 1.38 \\
\hline OLp - Ii & 66.6 & 86.2 & 79.44 & 4.98 & 68.6 & 89.2 & 80.71 & 5.16 & 1.27 \\
\hline Overjet & -4.2 & 0.4 & -2.18 & 1.02 & -4.4 & 0.0 & -2.07 & 0.94 & 0.11 \\
\hline OLp - Ms & 41.8 & 57.1 & 50.05 & 4.53 & 42.7 & 58.3 & 51.35 & 4.68 & 1.3 \\
\hline OLp - Mi & 44.5 & 63.1 & 53.73 & 5.92 & 44.5 & 64.8 & 55.0 & 6.03 & 1.27 \\
\hline Molar Rel. & -8.3 & 0.5 & -3.72 & 2.49 & -8.2 & -0.6 & -3.61 & 2.29 & 0.11 \\
\hline
\end{tabular}

Table11. Sagittal measurements at $t 0$ and $t 1$ in the Control Group

\begin{tabular}{|l|l|l|l|l|l|l|l|l|l|}
\hline Variables (mm or \%) & \multicolumn{2}{l}{ t0 } & \multicolumn{2}{ll}{ t1 } & t1 $-\mathrm{t} 0$ \\
\hline Vertical & Min & Max & Mean & & Min & Max & Mean & & $\begin{array}{l}\text { Mean } \\
\text { Difference }\end{array}$ \\
\hline Skeletal & & & & & & & & & \\
\hline OLparallel - A pt. & 21.2 & 40.4 & 30.82 & 6.14 & 24.8 & 42.1 & 32.78 & 5.85 & 1.96 \\
\hline N - Me & 99.0 & 117.2 & 108.76 & 4.46 & 99.0 & 118.0 & 110.21 & 4.54 & 1.45 \\
\hline ANS - Me & 56.9 & 66.4 & 61.02 & 3.05 & 56.1 & 67.0 & 61.63 & 3.05 & 0.61 \\
\hline Ar - GoI & 30.3 & 42.8 & 37.67 & 3.81 & 28.3 & 44.7 & 38.46 & 4.00 & 0.79 \\
\hline ANS-Me / N-Me & 0.54 & 0.59 & 0.56 & 0.002 & 0.53 & 0.59 & 0.56 & 0.02 & 0.0 \\
\hline Ar-GoI / ANS - Me & 0.54 & 0.72 & 0.62 & 0.06 & 0.53 & 0.73 & 0.62 & 0.06 & 0.0 \\
\hline Dental & & & & & & & & & \\
\hline Is - NL & 21.1 & 31.1 & 25.95 & 2.80 & 21.5 & 31.9 & 26.81 & 2.72 & 0.86 \\
\hline Ii - ML & 35.0 & 42.9 & 39.18 & 2.23 & 35.7 & 44.8 & 39.87 & 2.55 & 0.69 \\
\hline Overbite & 0.0 & 10.9 & 3.14 & 2.67 & 0.0 & 9.4 & 3.46 & 2.46 & 0.32 \\
\hline Msc - NL & 13.8 & 23.4 & 19.76 & 2.14 & 17.0 & 23.7 & 20.25 & 1.60 & 0.49 \\
\hline Mic - ML & 26.1 & 32.2 & 29.50 & 1.52 & 27.4 & 31.9 & 29.81 & 1.30 & 0.31 \\
\hline
\end{tabular}

Table 12. Vertical measurements at $t 0$ and $t 1$ in the Control Group. 


\begin{tabular}{|l|l|l|l|l|l|l|l|l|l|}
\hline Variables $\left(^{\circ}\right)$ & \multicolumn{7}{l}{ t0 } & \multicolumn{1}{l|}{ t1 } & t1 - t0 \\
\hline Angular & Min & Max & Mean & S.D. & Min & Max & Mean & S.D. & $\begin{array}{l}\text { Mean } \\
\text { Difference }\end{array}$ \\
\hline Skeletal & & & & & & & & & \\
\hline SNA & 76.7 & 85.0 & 81.84 & 2.73 & 76.9 & 86.2 & 82.14 & 2.97 & 0.3 \\
\hline SNB & 76.9 & 86.5 & 82.03 & 3.04 & 77.1 & 86.9 & 82.57 & 2.87 & 0.54 \\
\hline ANB & -3.9 & 3.7 & -0.19 & 2.18 & -3.8 & 3.2 & -0.43 & 2.10 & -0.24 \\
\hline N - S - Ar & 113.0 & 132.4 & 122.17 & 5.51 & 112.2 & 133.0 & 122.61 & 5.43 & 0.44 \\
\hline S - Ar - GoI & 137.2 & 156.1 & 145.61 & 4.72 & 136.9 & 156.8 & 144.61 & 4.52 & -1.0 \\
\hline Ar - GoI - Me & 116.4 & 137.2 & 126.41 & 6.81 & 166.6 & 145.2 & 127.21 & 8.51 & 0.8 \\
\hline Jarabak & 383.8 & 402.0 & 394.19 & 5.23 & 382.1 & 410.0 & 394.42 & 7.23 & 0.23 \\
\hline SNL - ML & 25.0 & 39.0 & 33.94 & 4.73 & 24.4 & 39.8 & 33.43 & 4.78 & -0.51 \\
\hline FH - ML & 20.0 & 36.8 & 27.44 & 4.92 & 21.0 & 37.1 & 27.22 & 4.58 & -0.22 \\
\hline SNL - OL & 13.0 & 30.0 & 21.01 & 5.63 & 13.1 & 29.1 & 20.79 & 5.20 & -0.22 \\
\hline SNL - NL & 3.5 & 13.1 & 8.98 & 3.15 & 1.8 & 12.9 & 8.21 & 3.34 & -0.77 \\
\hline Dental & & & & & & & & & \\
\hline Is - SNL & 89.3 & 122.2 & 104.98 & 8.98 & 91.0 & 121.4 & 107.47 & 8.66 & 2.49 \\
\hline Ii - ML & 67.7 & 105.1 & 90.94 & 8.62 & 71.8 & 107.0 & 90.36 & 9.56 & -0.58 \\
\hline
\end{tabular}

Table 13. Angular measurements at $t 0$ and $t 1$ in the Control Group

\begin{tabular}{|l|l|l|l|l|l|l|l|l|l|}
\hline Variables (mm) & \multicolumn{1}{l}{ t1 } & \multicolumn{3}{l|}{$\mathrm{t} 2$} & $\mathrm{t} 2-\mathrm{t} 1$ \\
\hline Sagittal & Min & Max & Mean & S.D. & Min & Max & Mean & S.D. & $\begin{array}{l}\text { Mean } \\
\text { Difference }\end{array}$ \\
\hline Skeletal & & & & & & & & & \\
\hline OLp - A pt. & 63.1 & 78.3 & 70.9 & 4.06 & 63.3 & 79.1 & 72.49 & 4.44 & 1.59 \\
\hline OLp - B pt. & 71.9 & 86.7 & 79.94 & 5.17 & 69.4 & 85.9 & 78.55 & 5.06 & -1.39 \\
\hline OLp - Pg & 72.5 & 90.9 & 81.44 & 5.76 & 69.1 & 88.7 & 80.35 & 5.81 & -1.09 \\
\hline Wits & -14.2 & -3 & -8.60 & 3.24 & -9.5 & 1.7 & -5.98 & 3.36 & 2.62 \\
\hline Co-A & 70.8 & 84.8 & 78.89 & 3.36 & 75.8 & 85.0 & 80.64 & 3.09 & 1.75 \\
\hline Co- Pg & 98.3 & 115.5 & 107.32 & 3.57 & 100.9 & 115.8 & 109.1 & 4.08 & 1.78 \\
\hline Co-Pg / Co-A & 22.3 & 33.3 & 28.43 & 2.72 & 19.2 & 33.2 & 28.45 & 3.63 & 0.02 \\
\hline Dental & & & & & & & & & \\
\hline OLp - Is & 66.2 & 87.4 & 78.64 & 5.13 & 72.9 & 90.9 & 82.28 & 4.65 & 3.64 \\
\hline OLp - Ii & 68.6 & 89.2 & 80.71 & 5.16 & 69.5 & 84.2 & 78.35 & 4.47 & -2.36 \\
\hline Overjet & -4.4 & 0.0 & -2.07 & 0.94 & 0.0 & 9.1 & 3.93 & 2.26 & 6.0 \\
\hline OLp - Ms & 42.7 & 58.3 & 51.35 & 4.68 & 46.6 & 64.1 & 54.1 & 5.06 & 2.75 \\
\hline OLp - Mi & 44.5 & 64.8 & 55.0 & 6.03 & 45.5 & 63.2 & 54.87 & 5.32 & -0.13 \\
\hline Molar Rel. & -8.2 & -0.6 & -3.61 & 2.29 & -5.9 & 1.8 & -0.78 & 2.15 & 2.83 \\
\hline
\end{tabular}

Table 14. Sagittal measurements at $\mathrm{t} 1$ and $\mathrm{t} 2$ for the Tooth anchored protraction facemask group 


\begin{tabular}{|c|c|c|c|c|c|c|c|c|c|}
\hline \multirow{2}{*}{$\begin{array}{l}\text { Variables (mm } \\
\text { or } \%)\end{array}$} & \multicolumn{4}{|l|}{$\mathrm{t} 1$} & \multicolumn{4}{|l|}{$\mathrm{t} 2$} & \multirow{2}{*}{$\begin{array}{l}\mathrm{t} 2-\mathrm{t} 1 \\
\text { Mean } \\
\text { Difference }\end{array}$} \\
\hline & Min & Max & Mean & & Min & Max & Mean & & \\
\hline \multicolumn{10}{|l|}{ Skeletal } \\
\hline $\begin{array}{l}\text { OLparallel - A } \\
\text { pt. }\end{array}$ & 24.8 & 42.1 & 32.78 & 5.85 & 27.2 & 47.9 & 35.98 & 5.46 & 3.2 \\
\hline $\mathrm{N}-\mathrm{Me}$ & 99.0 & 118.0 & 110.21 & 4.54 & 107.2 & 124.7 & 115.01 & 4.39 & 4.8 \\
\hline $\mathrm{ANS}-\mathrm{Me}$ & 56.1 & 67.0 & 61.63 & 3.05 & 58.3 & 71.7 & 64.33 & 3.79 & 2.7 \\
\hline $\mathrm{Ar}-\mathrm{GoI}$ & 28.3 & 44.7 & 38.46 & 4.00 & 32.0 & 45.8 & 38.96 & 4.03 & 0.5 \\
\hline ANS-Me / N-Me & 0.53 & 0.59 & 0.56 & 0.02 & 0.53 & 0.60 & 0.56 & 0.02 & 0.0 \\
\hline $\begin{array}{l}\text { Ar-GoI / ANS- } \\
\mathrm{Me}\end{array}$ & 0.53 & 0.73 & 0.62 & 0.06 & 0.52 & 0.73 & 0.62 & 0.07 & 0.0 \\
\hline \multicolumn{10}{|l|}{ Dental } \\
\hline Is $-\mathrm{NL}$ & 21.5 & 31.9 & 26.81 & 2.72 & 21.9 & 31.6 & 27.11 & 2.62 & 0.3 \\
\hline $\mathrm{Ii}-\mathrm{ML}$ & 35.7 & 44.8 & 39.87 & 2.55 & 36.9 & 44.6 & 40.65 & 1.99 & 0.78 \\
\hline Overbite & 0.0 & 9.4 & 3.46 & 2.46 & 0.0 & 4.0 & 2.17 & 1.11 & -1.29 \\
\hline $\mathrm{Msc}-\mathrm{NL}$ & 17.0 & 23.7 & 20.25 & 1.60 & 18.1 & 24.3 & 21.6 & 2.04 & 1.35 \\
\hline Mic-ML & 27.4 & 31.9 & 29.81 & 1.30 & 28.2 & 33.2 & 30.83 & 1.53 & 1.02 \\
\hline
\end{tabular}

Table 15. Vertical measurements at $t 1$ and $t 2$ for the Tooth anchored protraction facemask group

\begin{tabular}{|l|l|l|l|l|l|l|l|l|l|}
\hline Variables $\left(^{\circ}\right)$ & \multicolumn{7}{l}{$\mathrm{t} 1$} & \multicolumn{1}{l|}{$\mathrm{t} 2$} & $\mathrm{t}-\mathrm{t} 1$ \\
\hline Angular & Min & Max & Mean & S.D. & Min & Max & Mean & S.D. & $\begin{array}{l}\text { Mean } \\
\text { Difference }\end{array}$ \\
\hline Skeletal & & & & & & & & & \\
\hline SNA & 76.9 & 86.2 & 82.14 & 2.97 & 78.5 & 87.7 & 82.86 & 2.90 & 0.72 \\
\hline SNB & 77.1 & 86.9 & 82.57 & 2.87 & 75.8 & 84.8 & 80.77 & 2.37 & -1.8 \\
\hline ANB & -3.8 & 3.2 & -0.43 & 2.10 & -2.7 & 6.6 & 2.09 & 2.65 & 2.52 \\
\hline N - S - Ar & 112.2 & 133.0 & 122.61 & 5.43 & 114.6 & 132.6 & 123.11 & 4.48 & 0.5 \\
\hline S - Ar - GoI & 136.9 & 156.8 & 144.61 & 4.52 & 142.7 & 164.4 & 147.96 & 5.21 & 3.35 \\
\hline Ar - GoI - Me & 166.6 & 145.2 & 127.21 & 8.51 & 118.7 & 137.0 & 126.25 & 6.58 & -0.96 \\
\hline Jarabak & 382.1 & 410.0 & 394.42 & 7.23 & 388.0 & 414.4 & 397.31 & 5.93 & 2.89 \\
\hline SNL - ML & 24.4 & 39.8 & 33.43 & 4.78 & 28.5 & 43.1 & 35.86 & 4.34 & 2.43 \\
\hline FH - ML & 21.0 & 37.1 & 27.22 & 4.58 & 23.1 & 37.9 & 29.64 & 4.36 & 2.42 \\
\hline SNL - OL & 13.1 & 29.1 & 20.79 & 5.20 & 11.5 & 25.1 & 18.73 & 4.38 & -2.06 \\
\hline SNL - NL & 1.8 & 12.9 & 8.21 & 3.34 & 4.7 & 12.5 & 8.22 & 2.13 & 0.01 \\
\hline Dental & & & & & & & & & \\
\hline Is - SNL & 91.0 & 121.4 & 107.47 & 8.66 & 98.9 & 118.2 & 109.75 & 6.71 & 2.28 \\
\hline Ii - ML & 71.8 & 107.0 & 90.36 & 9.56 & 76.0 & 100.0 & 85.16 & 7.39 & -5.2 \\
\hline Tabl 16. Angur
\end{tabular}

Table 16. Angular measurements at $\mathrm{t} 1$ and $\mathrm{t} 2$ for the Tooth anchored protraction facemask group 


\begin{tabular}{|l|l|l|l|l|l|l|l|l|l|}
\hline Variables (mm) & \multicolumn{4}{l}{ T1 } & \multicolumn{4}{l|}{ T2 } & \multicolumn{4}{l|}{ T2 - T1 } \\
\hline Sagittal & Min & Max & Mean & S.D. & Min & Max & Mean & S.D. & $\begin{array}{l}\text { Mean } \\
\text { Difference }\end{array}$ \\
\hline Skeletal & & & & & & & & & \\
\hline OLp - A pt. & 60.0 & 76.9 & 66.74 & 3.93 & 61.9 & 78.7 & 68.28 & 4.32 & 1.54 \\
\hline OLp - B pt. & 63.5 & 80.0 & 71.86 & 5.13 & 62.8 & 80.6 & 70.57 & 5.41 & -1.29 \\
\hline OLp - Pg & 66.7 & 84.0 & 73.95 & 4.70 & 65.8 & 84.1 & 73.82 & 5.11 & -0.13 \\
\hline Wits & -9.6 & 0.2 & -5.12 & 2.58 & -6.9 & 6.9 & -2.54 & 3.22 & 2.58 \\
\hline Co-A & 65.2 & 81.9 & 73.02 & 4.09 & 68.6 & 82.6 & 75.57 & 4.27 & 2.55 \\
\hline Co- Pg & 82.9 & 104.3 & 97.19 & 5.50 & 88.2 & 108.7 & 100.59 & 5.13 & 3.4 \\
\hline Co-Pg / Co-A & 17.7 & 33.2 & 24.17 & 3.89 & 18.5 & 32.4 & 25.03 & 4.29 & 0.86 \\
\hline Dental & & & & & & & & & \\
\hline OLp - Is & 60.1 & 79.3 & 70.28 & 4.67 & 60.3 & 84.4 & 72.47 & 5.57 & 2.19 \\
\hline OLp - Ii & 61.9 & 79.0 & 71.14 & 4.67 & 55.4 & 80.9 & 69.88 & 5.52 & -1.26 \\
\hline Overjet & -4.8 & 2.9 & -0.86 & 2.31 & -1.6 & 5.9 & 2.6 & 1.76 & 3.46 \\
\hline OLp - Ms & 40.2 & 50.7 & 44.45 & 3.18 & 41.1 & 58.0 & 46.89 & 4.27 & 2.44 \\
\hline OLp - Mi & 41.3 & 55.2 & 47.52 & 4.20 & 42.2 & 59.1 & 48.94 & 4.65 & 1.42 \\
\hline Molar Rel. & -0.6 & -7.0 & -3.34 & 1.65 & -4.9 & 0.4 & -2.05 & 1.62 & 1.29 \\
\hline
\end{tabular}

Table 17. Sagittal Measurements at $\mathrm{T} 1$ and $\mathrm{T} 2$ for the Bone anchored protraction facemask group

\begin{tabular}{|l|l|l|l|l|l|l|l|l|l|}
\hline $\begin{array}{l}\text { Variables (mm or } \\
\text { \%) }\end{array}$ & \multicolumn{3}{l}{ T1 } \\
\hline Vertical & Min & Max & Mean & S.D. & Min & Max & Mean & S.D. & $\begin{array}{l}\text { Mean } \\
\text { Difference }\end{array}$ \\
\hline Skeletal & & & & & & & & & \\
\hline OLparallel - A pt. & 16.4 & 38.9 & 30.14 & 5.43 & 16.5 & 41.3 & 31.62 & 6.07 & 1.48 \\
\hline N - Me & 90.0 & 111.0 & 100.46 & 5.98 & 95.8 & 117.7 & 104.31 & 5.98 & 3.85 \\
\hline ANS - Me & 49.1 & 65.5 & 57.94 & 5.16 & 50.3 & 69.2 & 60.2 & 5.09 & 2.26 \\
\hline Ar - GoI & 30.1 & 45.9 & 35.16 & 4.31 & 29.9 & 48.0 & 36.59 & 4.72 & 1.43 \\
\hline ANS-Me / N-Me & 0.52 & 0.63 & 0.58 & 0.03 & 0.52 & 0.62 & 0.58 & 0.03 & 0.0 \\
\hline Ar-GoI / ANS-Me & 0.49 & 0.78 & 0.61 & 0.08 & 0.47 & 0.79 & 0.61 & 0.09 & 0.0 \\
\hline Dental & & & & & & & & & \\
\hline Is - NL & 14.4 & 27.7 & 22.41 & 3.69 & 19.9 & 29.0 & 24.58 & 2.61 & 2.17 \\
\hline Ii - ML & 27.9 & 39.9 & 34.82 & 3.45 & 29.7 & 41.2 & 36.08 & 3.11 & 1.26 \\
\hline Overbite & -1.1 & 5.9 & 1.56 & 2.18 & -1.8 & 4.4 & 1.42 & 1.48 & -0.14 \\
\hline Msc - NL & 9.1 & 21.9 & 17.02 & 3.00 & 11.8 & 22.9 & 18.58 & 2.73 & 1.56 \\
\hline Mic - ML & 23.3 & 30.5 & 26.51 & 2.06 & 23.9 & 32.9 & 27.7 & 2.13 & 1.19 \\
\hline
\end{tabular}

Table 18. Vertical measurements at $\mathrm{t} 1$ and $\mathrm{t} 2$ in Control Group 


\begin{tabular}{|l|l|l|l|l|l|l|l|l|l|}
\hline Variables $\left(^{(}\right)$ & \multicolumn{9}{l|}{ T1 } \\
\hline Angular & Min & Max & Mean & S.D. & Min & Max & Mean & S.D. & Mean Difference \\
\hline Skeletal & & & & & & & & & \\
\hline SNA & 71.9 & 92.1 & 80.29 & 4.74 & 73.0 & 91.2 & 81.88 & 4.49 & 1.59 \\
\hline SNB & 74.8 & 90.2 & 81.2 & 4.17 & 71.9 & 88.8 & 80.4 & 4.25 & -0.8 \\
\hline ANB & -5.5 & 3.3 & -0.92 & 2.78 & -3.8 & 6.9 & 1.48 & 2.76 & 2.4 \\
\hline N - S - Ar & 107.9 & 131.1 & 118.69 & 5.59 & 107.5 & 131.4 & 120.37 & 6.82 & 1.68 \\
\hline S - Ar - GoI & 133.8 & 152.7 & 143.63 & 5.87 & 129.4 & 158.4 & 142.49 & 7.31 & -1.14 \\
\hline Ar - GoI - Me & 116.6 & 146.1 & 132.29 & 7.02 & 115.9 & 146.1 & 131.02 & 7.12 & -1.27 \\
\hline Jarabak & 380.7 & 413.2 & 394.66 & 7.27 & 382.3 & 410.8 & 393.88 & 8.15 & -0.78 \\
\hline SNL - ML & 22.2 & 44.9 & 32.62 & 6.07 & 21.1 & 49.5 & 32.86 & 7.13 & 0.24 \\
\hline FH -ML & 15.0 & 34.0 & 25.6 & 5.19 & 15.0 & 40.1 & 26.04 & 6.41 & 0.44 \\
\hline SNL - OLs & 9.0 & 29.4 & 18.14 & 5.89 & 7.2 & 32.0 & 17.31 & 6.09 & -0.83 \\
\hline SNL - NL & 2.6 & 12.9 & 6.44 & 3.07 & 1.1 & 14.0 & 6.52 & 3.68 & 0.08 \\
\hline Dental & & & & & & & & & \\
\hline Is - SNL & 87.2 & 121.8 & 103.19 & 8.23 & 86.8 & 114.2 & 101.16 & 8.12 & -2.03 \\
\hline Ii - ML & 78.1 & 91.9 & 84.75 & 3.48 & 77.8 & 95.6 & 83.08 & 4.54 & -1.67 \\
\hline Table 19. Ang & & & & &
\end{tabular}

Table 19. Angular measurements at $t 1$ and $t 2$ in Control Group 


\begin{tabular}{|c|c|c|c|c|c|c|}
\hline \multirow[t]{2}{*}{ Variable Name } & \multicolumn{2}{|c|}{$\begin{array}{l}\text { Tooth anchored } \\
\text { protraction facemask }\end{array}$} & \multicolumn{2}{|c|}{$\begin{array}{l}\text { Bone anchored protraction } \\
\text { facemask }\end{array}$} & \multicolumn{2}{|c|}{$\begin{array}{l}\text { ANOVA } \\
\text { Between Tooth and Bone } \\
\text { anchored }\end{array}$} \\
\hline & $\begin{array}{l}\text { Mean } \\
\text { Difference }\end{array}$ & $\mathrm{SD}$ & $\begin{array}{l}\text { Mean } \\
\text { Difference }\end{array}$ & $\mathrm{SD}$ & p-value & Sig \\
\hline \multicolumn{7}{|l|}{ Skeletal } \\
\hline 1. OLp - A pt. & 0.76 & 1.38 & 0.71 & 1.23 & 0.89 & N.S. \\
\hline 2. OLp - B pt. & -2.43 & 1.52 & -1.43 & 2.27 & 0.86 & N.S. \\
\hline 3. OLp - Pg & -2.20 & 2.24 & -1.24 & 3.05 & 0.26 & N.S. \\
\hline 4. Wits & 2.33 & 2.91 & 2.29 & 2.40 & 0.96 & N.S. \\
\hline 5. $\mathrm{Co}-\mathrm{A}$ & 0.06 & 1.63 & 0.85 & 3.06 & 0.31 & N.S. \\
\hline 6. $\mathrm{Co}-\mathrm{Pg}$ & 0.62 & 2.63 & 1.00 & 4.76 & 0.18 & N.S. \\
\hline 7. Co-Pg - Co-A & -0.68 & 3.33 & 0.14 & 3.40 & 0.44 & N.S. \\
\hline \multicolumn{7}{|l|}{ Dental } \\
\hline 8. OLp-Is & 2.26 & 1.30 & 0.82 & 2.43 & 0.024 & * \\
\hline 9. OLp-Ii & -3.62 & 2.47 & -2.53 & 2.26 & 0.15 & N.S. \\
\hline 10. Overjet & 5.88 & 2.13 & 3.35 & 2.45 & 0.001 & * \\
\hline 11. OLp-Ms & 1.44 & 1.61 & 1.13 & 1.78 & 0.56 & N.S. \\
\hline 12. OLp - Mi & -1.39 & 2.05 & 0.16 & 2.93 & 0.059 & N.S. \\
\hline 13. Molar Relationship & 2.72 & 1.65 & 1.16 & 1.99 & 0.011 & * \\
\hline \multicolumn{7}{|l|}{ Skeletal } \\
\hline 14. OLparallel - A pt & 1.23 & 2.13 & -0.48 & 1.40 & 0.004 & $*$ \\
\hline 15. $\mathrm{N}-\mathrm{Me}$ & 3.35 & 2.28 & 2.40 & 2.46 & 0.21 & N.S. \\
\hline 16. ANS - Me & 2.09 & 2.30 & 1.66 & 2.20 & 0.54 & N.S. \\
\hline 17. $\mathrm{Ar}-\mathrm{GoI}$ & -0.30 & 2.51 & 0.64 & 2.91 & 0.28 & N.S. \\
\hline 18. ANS $-\mathrm{Me} / \mathrm{N}-\mathrm{Me}$ & 0.003 & 0.01 & 0.001 & 0.01 & 0.53 & N.S. \\
\hline 19. $\mathrm{Ar}-\mathrm{GoI} / \mathrm{ANS}-\mathrm{Me}$ & -0.008 & 0.02 & 0.001 & 0.05 & 0.54 & N.S. \\
\hline \multicolumn{7}{|l|}{ Dental } \\
\hline 20. Is - NL & -0.55 & 1.60 & 1.30 & 2.80 & 0.014 & * \\
\hline 21. Ii-ML & 0.09 & 2.32 & 0.57 & 1.72 & 0.46 & N.S. \\
\hline 22. Overbite & -1.59 & 3.09 & -0.46 & 2.23 & 0.19 & N.S. \\
\hline 23. $\mathrm{Msc}-\mathrm{NL}$ & 0.85 & 1.66 & 1.06 & 1.86 & 0.70 & N.S. \\
\hline 24. Mic -ML & 0.71 & 1.45 & 0.88 & 1.38 & 0.69 & N.S. \\
\hline \multicolumn{7}{|l|}{ Skeletal } \\
\hline 25. SNA & 0.41 & 1.85 & 1.29 & 2.13 & 0.17 & N.S. \\
\hline 26. SNB & -2.34 & 1.61 & -1.34 & 1.99 & 0.08 & N.S. \\
\hline 27. ANB & 2.75 & 1.92 & 2.63 & 2.41 & 0.85 & N.S. \\
\hline 28. $\mathrm{N}-\mathrm{S}-\mathrm{Ar}$ & 0.07 & 2.74 & 1.24 & 3.37 & 0.23 & N.S. \\
\hline 29. $\mathrm{S}-\mathrm{Ar}-\mathrm{GoI}$ & 4.34 & 5.55 & -0.14 & 3.71 & 0.004 & $*$ \\
\hline 30. $\mathrm{Ar}-\mathrm{GoI}-\mathrm{Me}$ & -1.75 & 5.57 & -2.06 & 3.73 & 0.83 & N.S. \\
\hline 31. Jarabak & 2.65 & 7.42 & -1.01 & 4.18 & 0.06 & N.S. \\
\hline 32. $\mathrm{SNL}-\mathrm{ML}$ & 2.94 & 1.42 & 0.74 & 2.90 & 0.004 & $*$ \\
\hline 33. $\mathrm{FH}-\mathrm{ML}$ & 2.64 & 2.49 & 0.66 & 2.85 & 0.025 & $*$ \\
\hline 34. SNL-OL & -1.84 & 4.15 & -0.61 & 3.33 & 0.30 & N.S. \\
\hline 35. SNL-NL & 0.77 & 2.89 & 0.84 & 2.15 & 0.92 & N.S. \\
\hline \multicolumn{7}{|l|}{ Dental } \\
\hline 36. Is - SNL & -0.21 & 7.82 & -4.52 & 5.67 & 0.053 & N.S. \\
\hline 37. Ii-ML & -4.61 & 8.18 & -1.08 & 3.84 & 0.08 & N.S. \\
\hline
\end{tabular}

Table 20. Comparison of the Mean Difference Between Tooth Anchored and Bone Anchored Groups

$\mathrm{NS}=$ not significantly different, ${ }^{*}=$ significantly different at $\mathrm{p}<0.05$. 


\begin{tabular}{|l|l|}
\hline Overjet & Molar relationship \\
\hline Skeletal contribution & Skeletal contribution: \\
\hline 1. OLp - A pt. & 1. OLp - A pt. \\
\hline 2. OLp - Pg & 2. OLp - Pg \\
\hline Dental contribution & Dental contribution \\
\hline 3. OLp - Is minus OLp - A pt. & 3. OLp - Ms minus OLp - A pt. \\
\hline 4. OLp - Ii minus OLp - Pg & 4. OLp - Mi minus OLp - Pg \\
\hline Overjet correction & Molar relationship correction \\
\hline Sum of $1,2,3$, and 4 & Sum of 1,2,3, and 4 \\
\hline
\end{tabular}

\section{Table 21. Calculation of Overjet and Molar Relationship Changes}

The forward and downward movement of the maxilla (OLp-A) will change the position of the measuring points associated with the sagittal dental variables OLp-Is and OLp-Ms, making them more positive than they truly are.

The downward and backward movement of the mandible (OLp-Pg) will change the position of the measuring points associated with the sagittal dental variables OLp-Ii and OLp-Mi, making them more negative than they truly are.

The following figures and calculations quantify the overjet correction for the tooth anchored group (Figure 7) and the bone anchored group (Figure 8), and the molar correction for the tooth anchored group (Figure 9) and the bone anchored group (Figure 10). 


\begin{tabular}{|c|}
\hline Maxilla $=$ OLp-A pt. (0.8) \\
\hline Maxillary incisor $=$ OLp-Is (2.3) minus OLp-A pt. (0.8) $=1.5$ \\
\hline Mandible $=$ OLp-Pg (-2.2) \\
\hline Mandibular incisor $=$ OLp-Ii (-3.6) minus OLp-Pg $(-2.2)=-1.4$ \\
\hline
\end{tabular}
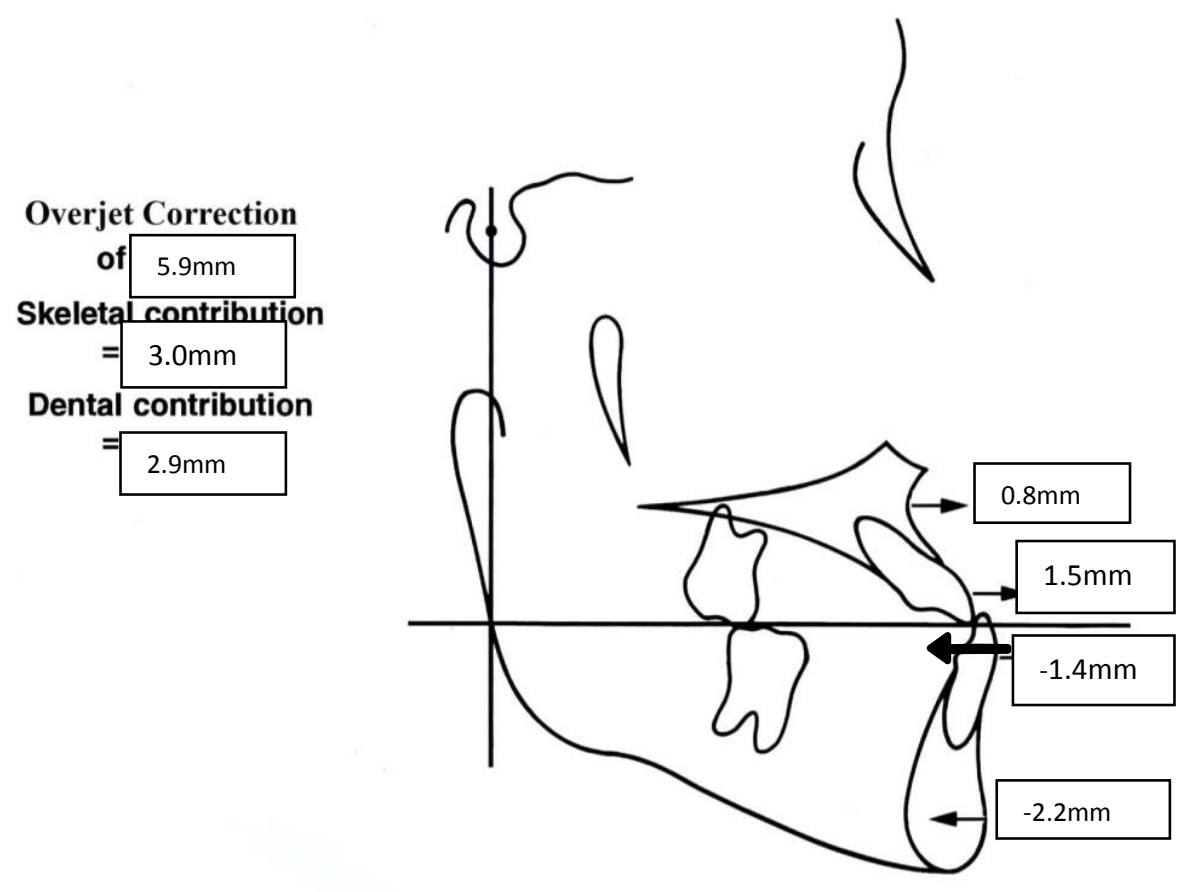

Figure 7: Skeletal and dental contributions to overjet correction for the tooth anchored protraction facemask group

Overjet Correction (5.9) $=$ Maxilla (0.8 mm) + Mx incisor (1.5) - Mandible (-2.2) - Md incisor (-1.4) Overjet Correction (5.9) = Maxilla (14\%) + Mx incisor (25\%) - Mandible (37\%) - Md incisor (24\%) 


\begin{tabular}{|c|}
\hline Maxilla $=$ OLp-A pt. (0.7) \\
\hline Maxillary incisor= OLp-Is (0.8) minus OLp-A pt. (0.7) $=0.1$ \\
\hline Mandible $=$ OLp-Pg (-1.2) \\
\hline Mandibular incisor= OLp-Ii (-2.5) minus OLp-Pg $(-1.2)=-1.3$ \\
\hline
\end{tabular}
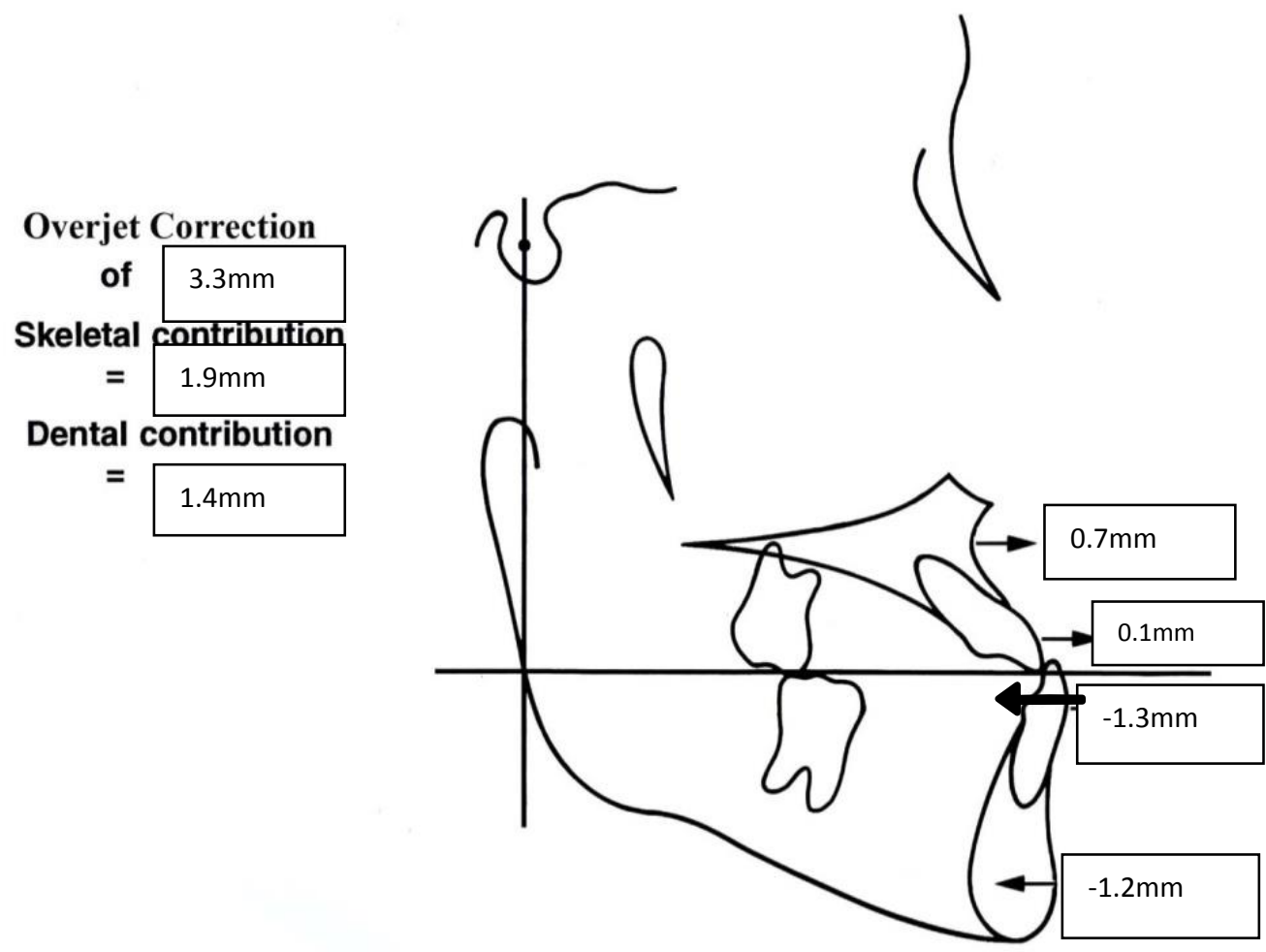

Figure 8: Skeletal and dental contributions to overjet correction for the bone anchored protraction facemask group

Overjet Correction (3.3)= Maxilla (0.7 mm) + Mx incisor (0.1) - Mandible (-1.2) - Md incisor (-1.3) Overjet Correction (3.3)= Maxilla (22\%) + Mx incisor (1\%) - Mandible (37\%) - Md incisor (40\%) 


\begin{tabular}{|c|}
\hline Maxilla $=$ OLp-A pt. (0.8 ) \\
\hline Maxillary molar= OLp-Ms (1.4) minus OLp-A pt. (0.8) $=0.6$ \\
\hline Mandible $=$ OLp-Pg (-2.2) \\
\hline Mandibular molar= OLp-Mi (-1.4) minus OLp-Pg $(-2.2)=0.8$ \\
\hline
\end{tabular}
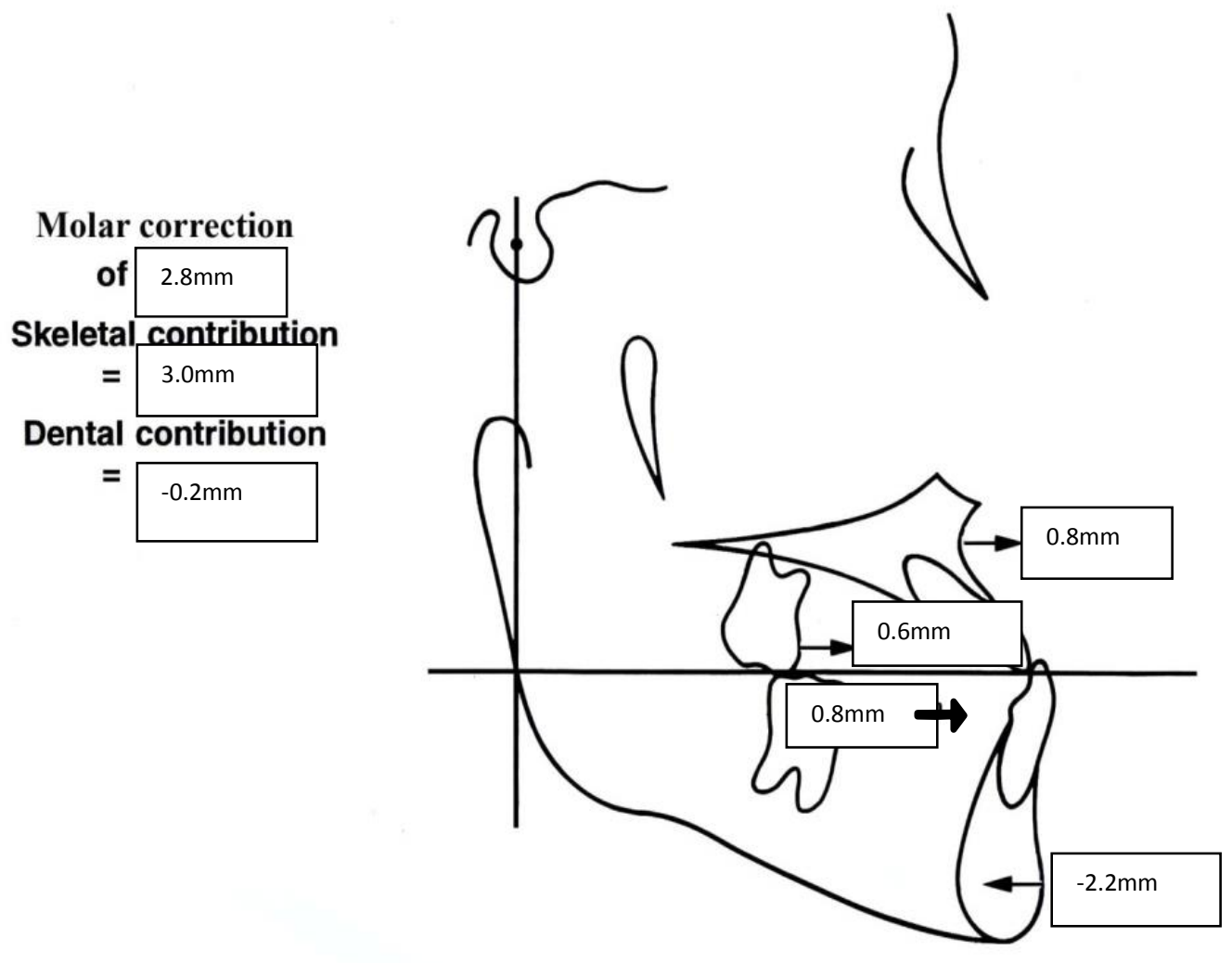

Figure 9: Skeletal and dental contributions to molar relationship correction for the tooth anchored protraction facemask group

Molar Relationship Correction (2.8) = Max (0.8) + Mx molar (0.6) - Mand (-2.2) - Md molar(0.8) (-0.6) 


\begin{tabular}{|c|}
\hline Maxilla $=$ OLp-A pt. (0.7) \\
\hline Maxillary molar= OLp-Ms (1.1) minus OLp-A pt. (0.7) $=0.4$ \\
\hline Mandible $=$ OLp-Pg (-1.2) \\
\hline Mandibular molar= OLp-Mi (0.1) minus OLp-Pg (-1.2) $=1.3$ \\
\hline
\end{tabular}
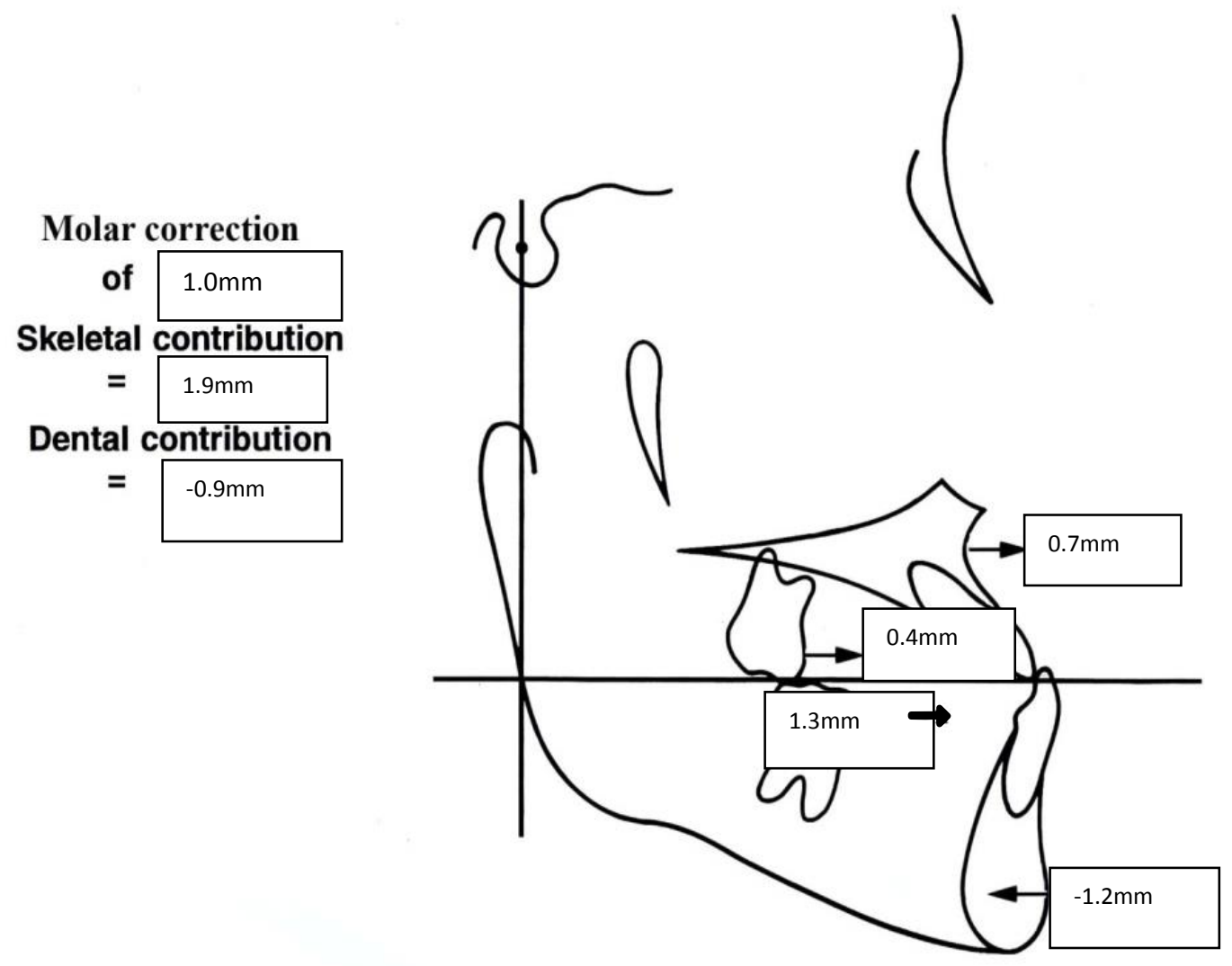

Figure 10: Skeletal and dental contributions to molar relationship correction for the bone anchored protraction facemask group

Molar Relationship Correction (1.0) = Max (0.7) + Mx molar (0.4) - Mand (-1.2) - Md molar (1.3) 


\section{CHAPTER V: DISCUSSION}

Three variables were statistically significant between the two groups in the sagittal dimension. There were significantly greater changes in overjet in the tooth anchored group $(5.9 \mathrm{~mm})$ than bone anchored group $(3.3 \mathrm{~mm}, \mathrm{p}<.001)$. A significantly greater difference in change in molar relationship in the tooth anchored group $(2.7 \mathrm{~mm})$ than bone anchored group $(1.1 \mathrm{~mm}, \mathrm{p}<.05)$ was found in this study. There was a statistically significant difference in overjet correction in the tooth anchored group $(5.88 \mathrm{~mm})$ compared to the bone anchored group $(3.35 \mathrm{~mm})$.

No significant difference in forward movement of A point between the tooth anchored and bone anchored groups was found: $0.76 \mathrm{~mm}$ forward movement for tooth anchored group and $0.71 \mathrm{~mm}$ forward movement for bone anchored group. A point measurement in this study was found to be smaller than results that Ngan et al measured of $2.1 \mathrm{~mm}^{103}$. There was significantly more proclination of maxillary incisors in the tooth anchored group $(2.3 \mathrm{~mm})$ than bone anchored group $(0.8 \mathrm{~mm}, \mathrm{p}<.05)$. This excess proclination contributes to greater overjet correction in tooth anchored group, but this is one of the potential negative side effects that occur with conventional protraction facemask therapy that was noted in the literature review ${ }^{30,31}$.

There were no significant differences in forward movement of maxillary molars between tooth anchored group $(0.6 \mathrm{~mm})$ than bone anchored group $(0.4 \mathrm{~mm})$. Although there was no significant difference, there were many individual variations between patients, with a range of $-2.1 \mathrm{~mm}$ to $4.6 \mathrm{~mm}$ for the tooth anchored group and $-0.8 \mathrm{~mm}$ to $3.9 \mathrm{~mm}$ for the bone anchored group. The results for this study for molar mesial movement matched Dr. Wilmes' finding of $0.4 \mathrm{~mm}$ on the right and $0.3 \mathrm{~mm}$ on the left ${ }^{37}$. Although no measurements were taken for the miniscrews used in this study, Liou et al found that miniscrews do not remain absolutely stationary throughout orthodontic loading ${ }^{141}$. This study found that Wits improved $2.3 \mathrm{~mm}$, which closely matches Dr. Wilmes' finding of $2.7 \mathrm{~mm}$ improvement of Wits ${ }^{37}$. 
Two variables were statistically significant between the two groups in the vertical dimension. This study found a significantly greater downward movement of the maxilla for the tooth anchored (1.2mm) than the bone anchored group $(-0.5 \mathrm{~mm}, \mathrm{p}<.005)$. This finding could be due to direction of force application for facemask being different between the two groups - 20-30 degree direction of elastics in bone anchored group versus 30-45 degree direction of elastics in tooth anchored group. The decreased downward movement of the maxilla helps prevent downward and backward rotation of the mandible in the bone anchored group (OLp-Pg $-1.2 \mathrm{~mm}$ versus $-2.2 \mathrm{~mm}$ ). This study also found a significantly greater downward movement of the maxillary incisors between the bone anchored group $(1.3 \mathrm{~mm})$ than tooth anchored group $(-0.55 \mathrm{~mm}, \mathrm{p}<.05)$. This finding helps contribute to maintaining overbite in the bone anchored group versus $1.6 \mathrm{~mm}$ decrease in overbite in tooth anchored group.

Three variables were statistically significant between the two groups in the angular dimension. This study found a significantly greater increase in mandibular plane angle in the tooth anchored group (SNLML 2.9 degree, FH-ML 2.6 degree) compared to bone anchored group (SNL-ML 0.7 degree, FH-ML 0.7 degree, $\mathrm{p}<.05$ ). This finding occurs as a result of the Articular angle significantly increasing in the tooth anchored group (4.3 degrees vs. -0.1 degrees), as well as the greater downward movement of the maxilla in the tooth anchored group $(1.3 \mathrm{~mm}$ vs. $-0.55 \mathrm{~mm})$. The results show that the mandibular plane angle increase does not occur as a result of extrusion of the molars (same amount of extrusion of molars between the two groups). The mandibular plane increase in the tooth anchored group could also be contributed to if there was a bigger $\mathrm{CO} / \mathrm{CR}$ discrepancy in the tooth anchored group than the bone anchored group. 


\section{CHAPTER VI: SUMMARY AND CONCLUSIONS}

\section{SUMMARY}

The purpose of this study was to quantify and compare skeletal and dental changes between tooth anchored and bone anchored maxillary protraction in Class III patients, as determined from lateral cephalogram radiographs. Sagittal, vertical and angular variables were analyzed to determine skeletal and dental changes.

This retrospective cephalometric study utilized a custom cephalometric analysis based on variables described by Steiner, WITS, McNamara, Panchez, and Tweed. One-way ANOVA test was used to evaluate the findings. The following hypotheses were tested:

1. There is no difference in treatment effects for sagittal variables between the tooth anchored and bone anchored protraction facemask groups.

2. There is no difference in treatment effects for vertical variables between the tooth anchored and bone anchored protraction facemask groups.

3. There is no difference in treatment effects for angular variables between the tooth anchored and bone anchored protraction facemask groups.

\section{CONCLUSION}

All three null hypotheses are rejected because this study found that there were significant differences in sagittal, vertical and angular dimensions of Class III patients treated with tooth anchored maxillary expansion and protraction versus bone anchored maxillary expansion and protraction. The two treatment groups had similar results in the forward movement of A point, similar changes in Wits and 
ANB values, and both corrected the overjet and molar relationship. There was a similar amount of forward movement of the maxillary molars between the treatment groups. There was statistically significant less downward movement of the maxillary in the bone anchored group, which also contributed to less downward and backward rotation of the mandible. There was less of an increase in the mandibular plane angle, less proclination of incisors, less increase in lower face height and less decrease in oberbite in the bone anchored group.

It can be concluded that although both treatment moldalites give similar results with movement of A point, the bone anchored maxillary protraction does have less of the negative side effects that occur with tooth anchored maxillary protraction. Traditional tooth born facemask therapy is most effective when treating skeletal Class III malocclusions with a retrusive maxilla and a hypodivergent growth pattern. The Hybrid hyrax tooth born facemask therapy may be a better treatment alternative for patients with a hyperdivergent growth pattern due to the decreased downward movement of A point, the decreased mandibular plane values, and a minimized increase in lower face height. 


\section{CHAPTER VII: RECOMMENDATION FOR FUTURE RESEARCHES}

1. Repeat this study with larger sample sizes.

2. Repeat this study with an observation period for the bone anchored group.

3. Repeat this study with long term follow ups to determine stability of treatment.

4. Design a study to compare the Hybrid Hyrax appliance to complete skeletal anchorage from protraction facemask attached to miniplates (at the infrazygomatic area or the lateral nasal wall).

5. Design a study to compare this Hybrid Hyrax appliance to complete skeletal anchorage from miniplates in the maxilla and mandible with elastics (no protraction facemask). 


\section{REFERENCES}

1. Irie M, Nakamura S. Orthopedic approach to sever skeletal class III malocclusion. Am.J.Orthod. 975;67:377-392.

2. Allwright WC, Burndred WH. A survey of handicapping dentofacial anomalies among chinese in hong kong. Int Dent J. 1964;14:505-519.

3. Proffit WR, Fields HW,Jr, Moray LJ. Prevalence of malocclusion and orthodontic treatment need in the united states: Estimates from the NHANES III survey. Int J Adult Orthodon Orthognath Surg. 1998;13(2):97-106.

4. Ishii $\mathrm{H}$, Morita S, Takeuchi Y, Nakamura S. Treatment effect of combined maxillary protraction and chincap appliance in severe skeletal class III cases. American Journal of Orthodontics and Dentofacial Orthopedics. 1987;92(4):304-312.

5. Baik HS, Han HK, Kim DJ, Proffit WR. Cephalometric characteristics of korean class III surgical patients and their relationship to plans for surgical treatment. Int J Adult Orthodon Orthognath Surg. 2000;15(2):119-128.

6. Thilander B, Myberg N. The prevalence of malocclusion in swedish school children. Scand J Dent Res. $1973 ; 81: 12-20$

7. Haynes S. The prevalence of malocclusion $\mathrm{n}$ english school children aged 11-12 years. Trans Eur Orthod Soc. 1970:89-98.

8. Ellis III E, McNamara Jr. JA. Components of adult class III malocclusion. Journal of Oral and Maxillofacial Surgery. 1984;42(5):295-305. 
9. Guyer EC, Ellis EE, McNamara Jr. JA, Behrents RG. Components of class III malocclusion in juveniles and adolescents. Angle Orthodontist. 1986;56:7-30.

10. Mitani H, Sato K, Sugawara J. Growth of mandibular prognathism after pubertal growth peak. American Journal of Orthodontics and Dentofacial Orthopedics. 1993;104(4):330-336.

11. Singh GD. Morphologic determinants in the etiology of class III malocclusions: A review. Clinical Anatomy. 1999;12(5):382-405. doi: 10.1002/(SICI)1098-2353(1999)12:5<382::AID-CA9>3.0.CO;2-0.

12. Rey D, Angel D, Oberti G, Baccetti T. Treatment and posttreatment effects of mandibular cervical headgear followed by fixed appliances in class III malocclusion. American Journal of Orthodontics and Dentofacial Orthopedics. 2008;133(3):371-378.

13. Levin AS, McNamara Jr JA, Franchi L, Baccetti T, Fränkel C. Short-term and long-term treatment outcomes with the FR-3 appliance of fränkel. American Journal of Orthodontics and Dentofacial Orthopedics. 2008;134(4):513-524. doi: 10.1016/j.ajodo.2006.10.036.

14. Baccetti T. Long-term outcomes of class III treatment with mandibular cervical headgear followed by fixed appliances. Angle Orthod. 2009;79(5):828; 828-834; 834.

15. Reyes B. An estimate of craniofacial growth in class III malocclusion. Angle Orthod. 2006;76(4):577.

16. Riolo ML. Essentials for orthodontic practice. EFOP Pr; 2003.

17. Wolfe SM. Craniofacial growth of class III subjects six to sixteen years of age. Angle Orthod. 2011;81(2):211; 211-216; 216. 
18. Alexander AE, McNamara Jr. JA, Franchi L, Baccetti T. Semilongitudinal cephalometric study of craniofacial growth in untreated class III malocclusion. American Journal of Orthodontics and Dentofacial Orthopedics. 2009;135(6):700.e1-700.e14.

19. Innocenti C, Giuntini V, Defraia E, Baccetti T. Glenoid fossa position in class III malocclusion associated with mandibular protrusion. American Journal of Orthodontics and Dentofacial Orthopedics. 2009;135(4):438-441.

20. Ngan P. Early treatment of class III malocclusion: Is it worth the burden? American Journal of Orthodontics and Dentofacial Orthopedics. 2006;129(4, Supplement):S82-S85. doi: 10.1016/j.ajodo.2005.09.017.

21. Jacobson A, Evans WG, Preston CB, Sadowsky PL. Mandibular prognathism. Am J Orthod. 1974;66(2):140-171.

22. Baccetti T, Reyes BC, McNamara Jr JA. Craniofacial changes in class III malocclusion as related to skeletal and dental maturation. American Journal of Orthodontics and Dentofacial Orthopedics. 2007;132(2):171.e1-171.e12. doi: 10.1016/j.ajodo.2005.07.031.

23. Guyer E. Components of class III malocclusion in juveniles and adolescents. Angle Orthod. $1986 ; 56(1): 7$.

24. Nakasima A, Ichinose M, Nakata S, Takahama Y. Hereditary factors in the craniofacial morphology of angle's class II and class III malocclusions. Am J Orthod. 1982;82(2):150-156.

25. Xue F, Wong R, Rabie A. Genes, genetics, and class III malocclusion. Orthodontics \& Craniofacial Research. 2010;13(2):69-74. doi: 10.1111/j.1601-6343.2010.01485.x. 
26. Nakasima A, Ichinose M, Nakata S. Genetic and environmental factors in the development of socalled pseudo- and true mesioclusions. American Journal of Orthodontics and Dentofacial Orthopedics. $1986 ; 90(2): 106-116$.

27. Chang $\mathrm{H}$, Tseng $\mathrm{Y}$, Chang $\mathrm{H}$. Treatment of mandibular prognathism. J Formosan Med Assoc. 2006;105(10):781-790.

28. Markus AF, Precious DS. Effect of primary surgery for cleft lip and palate on mid-facial growth. British Journal of Oral and Maxillofacial Surgery. 1997;35(1):6-10.

29. Battagel JM. The aetiological factors in class III malocclusion. Eur.J.Orthod. 1993;15:347-370.

30. Soh J, Sandham A, Chan YH. Malocclusion severity in asian men in relation to malocclusion type and orthodontic treatment need. American Journal of Orthodontics and Dentofacial Orthopedics. 2005;128(5):648-652.

31. Kerr WJS, Philip Adams C. Cranial base and jaw relationship. Am J Phys Anthropol. 1988;77(2):213220. doi: 10.1002/ajpa.1330770209.

32. Cha B, Choi D, Ngan P, Jost-Brinkmann P, Kim S, Jang I. Maxillary protraction with miniplates providing skeletal anchorage in a growing class III patient. American Journal of Orthodontics and Dentofacial Orthopedics. 2011;139(1):99-112. doi: 10.1016/j.ajodo.2009.06.025.

33. Kokich VG, Shapiro PA, Oswald R, Koskinen-Moffett L, Clarren SK. Ankylosed teeth as abutments for maxillary protraction: A case report. Journal of orthodontics. 1985;88:303-307.

34. Singer S. Osseointegrated implants as an adjunct to facemask therapy: A case report. Angle Orthod. 2000;70(3):253. 
35. Hong H, Ngan P, Han GL, Liu GQ, Wei SHY. Use of onplants as stable anchorage for facemask treatment: A case report. Angle Orthod. 2005;75(3):453-460. Accessed 6 April 2012.

36. Enacar A, Giray B, Pehlivanoglu M, Iplikcioglu H. Facemask therapy with rigid anchorage in a patient with maxillary hypoplasia and severe oligodontia. American Journal of Orthodontics and Dentofacial Orthopedics. 2003;123(5):571-577. Accessed 6 April 2012.

37. Wilmes B, Nienkemper M, Drescher D. Application and effectiveness of a mini-implant- and toothborne rapid palatal expansion device: The hybrid hyrax. World J Orthod. 2010;11(4):323-330.

38. Wilmes B, Drescher D. A miniscrew system with interchangeable abutments. Journal of clinical orthodontics : JCO. 2008;42(10):574-580; quiz 595. Accessed 6 April 2012.

39. Cha B, Ngan PW. Skeletal anchorage for orthopedic correction of growing class III patients. Semin Orthod. 2011;17(2):124-137. doi: 10.1053/j.sodo.2010.12.005.

40. Kircelli BH, Pektas ZÖ, Uçkan S. Orthopedic protraction with skeletal anchorage in a patient with maxillary hypoplasia and hypodontia. Angle Orthodontist. 2006;76:156-163.

41. Kircelli BH, Pektas ZÖ. Midfacial protraction with skeletally anchored face mask therapy: A novel approach and preliminary results. American Journal of Orthodontics and Dentofacial Orthopedics. 2008;133(3):440-449. doi: 10.1016/j.ajodo.2007.06.011.

42. Zhou YH, Ding P, Lin Y, Qui LX. Facemask therapy with miniplate implant anchorage in a patient with maxillary hypoplasia. Chin Med J. 2007;15:1372-1375. 
43. Cevidanes L, Baccetti T, Franchi L, McNamara Jr. JA, De Clerck H. Comparison of two protocols for maxillary protraction: Bone anchors versus face mask with rapid maxillary expansion. Angle Orthod. 2010;80(5):799-806. Accessed 6 April 2012.

44. De Clerck H, Cevidanes L, Baccetti T. Dentofacial effects of bone-anchored maxillary protraction: A controlled study of consecutively treated class III patients. American Journal of Orthodontics and Dentofacial Orthopedics. 2010;138(5):577-581. doi: 10.1016/j.ajodo.2009.10.037.

45. De Clerck HJ, Cornelis MA, Cevidanes LH, Heymann GC, Tulloch CJF. Orthopedic traction of the maxilla with miniplates: A new perspective for treatment of midface deficiency. Journal of Oral and Maxillofacial Surgery. 2009;67(10):2123-2129. doi: 10.1016/j.joms.2009.03.007.

46. Wilmes B, Nienkemper M, Ludwig B, Kau CH, Drescher D. Early class III treatment with a hybrid hyrax-mentoplate combination. Journal of clinical orthodontics : JCO. 2011;45(1):15-21; quiz 39. Accessed 6 April 2012.

47. da Silva Filho OG, Magro AC, Capelozza Filho L. Early treatment of the class III malocclusion with rapid maxillary expansion and maxillary protraction. American Journal of Orthodontics and Dentofacial Orthopedics. 1998;113(2):196-203. doi: 10.1016/S0889-5406(98)70292-6.

48. Şar Ç, Arman-Özçırpıcı A, Uçkan S, Yazıcı AC. Comparative evaluation of maxillary protraction with or without skeletal anchorage. American Journal of Orthodontics and Dentofacial Orthopedics. 2011;139(5):636-649.

49. Ludwig B, Glas B, Bowman SJ, Drescher D, Wilmes B. Miniscrew-supported class III treatment with the hybrid RPE advancer. Journal of clinical orthodontics : JCO. 2010;44(9):533-539; quiz 561. Accessed 6 April 2012. 
50. Johnston LE. A comparative analysis of class II treatments, monograph 19. In: Craniofacial growth series. Ann Arbor, Michigan: ; 1986:103-148.

51. Proffit WR, Fields Jr HW, Sarver DM. Contemporary orthodontics. Elsevier Health Sciences; 2006.

52. Angle EH. Treatment of malocclusion of the teeth: Angle's system. White Dental Manufacturing Company; 1907.

53. Jacobson A, Jacobson RL, Rushton VE, et al. Radiographic cephalometry: From basics to 3-D imaging, (book/CD-ROM set). Vol 2006. ; 2007.

54. Soh J. Occlusal status in asian male adults: Prevalence and ethnic variation. Angle Orthod. $2005 ; 75(5): 814$.

55. Kelly JE, Harvey CR. An assessment of the occlusion of the teeth of youths 12-17 years. Vital Health Stat 11. 1977;(162)(162):1-65.

56. Garner L, Butt M. Malocclusion in black americans and nyeri kenyans: An epidemiologic study. Angle Orthod. 1985;55(2):139-146.

57. Proffit WR. Contemporary orthodontics. 4th ed. St. Louis: Mosby; 2006.

58. Silva RG, Kang DS. Prevalence of malocclusion among latino adolescents. American Journal of Orthodontics and Dentofacial Orthopedics. 2001;119(3):313-315.

59. Baccetti T, Reyes BC, McNamara Jr JA. Craniofacial changes in class III malocclusion as related to skeletal and dental maturation. American Journal of Orthodontics and Dentofacial Orthopedics. 2007;132(2):171.e1-171.e12. 
60. Enlow DH, Hans MG. Essentials of facial growth. Saunders Philadelphia; 1996.

61. Rakosi T, Schilli W. Class III anomalies: A coordinated approach to skeletal, dental, and soft tissue problems. J Oral Surg. 1981;39(11):860-870.

62. Adcock S, Markus A. Mid-facial growth following functional cleft surgery. British Journal of Oral and Maxillofacial Surgery. 1997;35(1):1-5.

63. Bjo"rk A, Skieller V. Facial development and tooth eruption: An implant study at the age of puberty. Am J Orthod. 1972;62(4):339-383.

64. Hopkin G. The cranial base as an aetiological factor in malocclusion*. Angle Orthod. 1968;38(3):250.

65. Kasai K, Moro T, Kanazawa E, Iwasawa T. Relationship between cranial base and maxillofacial morphology. Eur J Orthod. 1995;17(5):403-410.

66. Hong S, Yi C. A classification and characterization of skeletal class III on etio-pathogenic basis. Int J Oral Maxillofac Surg. 2001;30(4):264-271.

67. Miyajima K, McNamara Jr. JA, Sana M, Murata S. An estimation of craniofacial growth in the untreated class III female with anterior crossbite. American Journal of Orthodontics and Dentofacial Orthopedics. 1997;112(4):425-434.

68. Baccetti T, Antonini A, Franchi L, Tonti M, Tollaro I. Glenoid fossa position in different facial types: A cephalometric study. Br J Orthod. 1997;24(1):55-59.

69. Sato S. Case report: Developmental characterization of skeletal class III malocclusion. Angle Orthod. 1994;64(2):105. 
70. Chen F. Dental arch widths and mandibular-maxillary base width in class III malocclusions with low, average and high MP-SN angles. Angle Orthod. 2007;77(1):36; 36-41; 41.

71. Chen F, Terada K, Yang L, Saito I. Dental arch widths and mandibular-maxillary base widths in class III malocclusions from ages 10 to 14. American Journal of Orthodontics and Dentofacial Orthopedics. 2008;133(1):65-69.

72. Uysal T. Dental and alveolar arch widths in normal occlusion and class III malocclusion. Angle Orthod. 2005;75(5):809.

73. Franchi L, Baccetti T. Transverse maxillary deficiency in class II and class III malocclusions: A cephalometric and morphometric study on postero-anterior films. Orthodontics \& Craniofacial Research. 2005;8(1):21-28. doi: 10.1111/j.1601-6343.2004.00312.x.

74. Mitani H. Prepubertal growth of mandibular prognathism. Am J Orthod. 1981;80(5):546-553.

75. Zionic Alexander AE, McNamara Jr. JA, Franchi L, Baccetti T. Semilongitudinal cephalometric study of craniofacial growth in untreated class III malocclusion. American Journal of Orthodontics and Dentofacial Orthopedics. 2009;135(6):700.e1-700.e14. doi: 10.1016/j.ajodo.2008.06.025.

76. Mclntyre G. Treatment planning in class III malocclusion. DENTAL UPDATE-LONDON-. 2004;31(1):1321.

77. Pangrazio-Kulbersh V, Berger JL, Janisse FN, Bayirli B. Long-term stability of class III treatment: Rapid palatal expansion and protraction facemask vs LeFort I maxillary advancement osteotomy. American Journal of Orthodontics and Dentofacial Orthopedics. 2007;131(1):7.e9-7.e19. 
78. Turpin DL. Good time for discussion of early treatment. American Journal of Orthodontics and Dentofacial Orthopedics. 2000;118(3):247.

79. Robertson NRE. An examination of treatment changes in children treated with the function regulator of fränkel. Am J Orthod. 1983;83(4):299-310.

80. Frankel R. Maxillary retrusion in class 3 and treatment with the function corrector 3. Rep Congr Eur Orthod Soc. 1970:249-259.

81. Baik HS, Jee SH, Lee KJ, Oh TK. Treatment effects of fränkel functional regulator III in children with class III malocclusions. American Journal of Orthodontics and Dentofacial Orthopedics. 2004;125(3):294301. doi: 10.1016/j.ajodo.2003.04.016.

82. Loh MK, Kerr WJ. The function regulator III: Effects and indications for use. Br J Orthod. 1985;12(3):153-157.

83. Petit H. Adaptation following accelerated facial mask therapy. Clinical alterations of the growing face.Monograph. 1983;14.

84. McNamara Jr JA, Huge SA. The functional regulator (FR-3) of fränkel. Am J Orthod. 1985;88(5):409424.

85. Garattini G, Levrini L, Crozzoli P, Levrini A. Skeletal and dental modifications produced by the bionator III appliance. American Journal of Orthodontics and Dentofacial Orthopedics. 1998;114(1):4044.

86. Kidner G, DiBiase A, DiBiase D. Class III twin blocks: A case series. J Orthod. 2003;30(3):197-201. 
87. Seehra J, Fleming PS, Dibiase AT. Reverse twin block appliance for early dental class III correction. J Clin Orthod. 2010;44(10):602-10; quiz 621.

88. Atalay Z, Tortop T. Dentofacial effects of a modified tandem traction bow appliance. Eur J Orthod. 2010;32(6):655-661. doi: 10.1093/ejo/cjp153 [doi].

89. Üçem TT, Üçüncü N, Yüksel S. Comparison of double-plate appliance and facemask therapy in treating class III malocclusions. American Journal of Orthodontics and Dentofacial Orthopedics. 2004;126(6):672-679.

90. Huber R, Reynolds J. A dentofacial study of male students at the university of michigan in the physical hardening program. American journal of orthodontics and oral surgery. 1946;32(1):1-21.

91. HUMPHREYS HF, LEIGHTON BC. A survey of antero-posterior abnormalities of the jaws in children between the ages of 2 and 5 1/2 years of age. Br Dent J. 1950;88(1):3-15.

92. Sugawara J. Long-term effects of chincap therapy on skeletal profile in mandibular prognathism. American journal of orthodontics and dentofacial orthopedics. 1990;98(2):127; 127-133; 133.

93. Nukatska S. The longitudinal study of orthodopedic effects caused by chin cap treatment. Tohoku Univ Dent J. 1982;1:1-17.

94. Mitani H, Sakamoto T. Chin cap force to a growing mandible. long-term clinical reports. Angle Orthodontist. 1984;54:93-122.

95. Mitani H. Recovery growth of mandible after chin cup therapy: Fact or fiction. Seminars in orthodontics. 2007;13:186-199. 
96. Sakamoto T, Iwase I, Uka A, Nakamura S. A roentgenocephalometric study of skeletal changes during and after chin cup treatment. Am.J.Orthod. 1984;85:341-350.

97. Deguchi T. Case report KY: Functional analysis of a follow-up chin cup patient with TMJ pain. Angle Orthod. 1998;68(5):425.

98. Deguchi T. Clinical evaluation of temporomandibular joint disorders (TMD) in patients treated with chin cup. Angle Orthod. 1998;68(1):91.

99. Kim J, Viana MAG, Graber TM, Omerza FF, BeGole EA. The effectiveness of protraction face mask therapy: A meta-analysis. American Journal of Orthodontics and Dentofacial Orthopedics. 1999;115(6):675-685.

100. Haas J. Rapid expansion of the maxillary dental arch and nasal cavity by opening the mid-palatal suture. Angle Orthodontist. 1961;31:73-90.

101. McNamara JA. An orthopedic approach to the treatment of class III malocclusion in young patients. J Clin Orthod. 1987;21:598-608.

102. Turley PK. Orthopedic correction of class III malocclusion with palatal expansion and custom protraction headgear. J Clin Orthod. 1988;22:314-325.

103. Ngan P, Hägg U, Yiu C, Merwin D, Wei SHY. Soft tissue and dentoskeletal profile changes associated with maxillary expansion and protraction headgear treatment. American Journal of Orthodontics and Dentofacial Orthopedics. 1996;109(1):38-49.

104. Adkins MD, Nanda RS, Currier GF. Arch perimeter changes on rapid palatal expansion. American Journal of Orthodontics and Dentofacial Orthopedics. 1990;97(3):194-199. 
105. Garrett BJ, Caruso JM, Rungcharassaeng K, Farrage JR, Kim JS, Taylor GD. Skeletal effects to the maxilla after rapid maxillary expansion assessed with cone-beam computed tomography. American Journal of Orthodontics and Dentofacial Orthopedics. 2008;134:8-9.

106. Turley PK. Orthopedic correction of class III malocclusion with palatal expansion and custom protraction headgear. J Clin Orthod. 1988;22:314-325.

107. Wang Y, Chang PM, Liou EJ. Opening of circumaxillary sutures by alternate rapid maxillary expansions and constrictions. Angle Orthod. 2009;79(2):230-234.

108. Hata S, Itoh T, Nakagawa M, et al. Biomechanical effects of maxillary protraction on the craniofacial complex. Am.J.Orthod.Dentofacial Orthop. 1987;91:305-311.

109. Sarnas KV, Rune B. Extraoral traction to maxilla with face mask: A follow-up of 17 consecutively treated patients with and without cleft lip and palate. Cleft Palate J. 1987;24:95-103.

110. Wisth PJ, Tritrapunt A, Rygh P, Boe OE, Norderval K. The effect of maxillary protraction on front malocclusion and facial morphology. Acta Odont Scand. 1987;45:227-237.

111. Buschang PH, Porter C, Genecov E, Genecov D, Sayler KE. Face mask therapy of preadolescents with unilateral cleft lip and palate. Angle Orthodontist. 1994;64:145-150.

112. Baik HS. Clinical results of the maxillary protraction in korean children. Am.J.Orthod.Dentofacial Orthop. 1995;108:583-592.

113. Williams MD, Sarver DM, Sadowsky PL, Bradley E. Combined rapid maxillary expansion and protraction facemask in the treatment of class III malocclusions in growing children: A prospective longterm study. Semin Orthod. 1997;3(4):265-274. 
114. Baccetti T, McGill JS, Franchi L, McNamara Jr. JA, Tollaro I. Skeletal effects of early treatment of class III malocclusion with maxillary expansion and face-mask therapy. American Journal of Orthodontics and Dentofacial Orthopedics. 1998;113(3):333-343.

115. da Silva Filho OG, Magro AC, Capelozza Filho L. Early treatment of the class III malocclusion with rapid maxillary expansion and maxillary protraction. American Journal of Orthodontics and Dentofacial Orthopedics. 1998;113(2):196-203.

116. Baccetti T, McGill JS, Franchi L, McNamara Jr. JA, Tollaro I. Skeletal effects of early treatment of class III malocclusion with maxillary expansion and face-mask therapy. American Journal of Orthodontics and Dentofacial Orthopedics. 1998;113(3):333-343. doi: 10.1016/S0889-5406(98)70306-3.

117. Ngan PW, Hagg U, Yiu C, Wei SHY. Treatment response and long-term dentofacial adaptations to maxillary expansion and protraction. Semin Orthod. 1997;3(4):255-264.

118. Chong Y. Changes following the use of protraction headgear for early correction of class III malocclusion. Angle Orthod. 1996;66(5):351.

119. Merwin D, Ngan P, Hägg U, Yiu C, Wei SH. Timing for effective application of anteriorly directed orthopedic force to the maxilla. Am.J.Orthod.Dentofacial Orthop. 1997;112:292-299.

120. Cozza P, Baccetti T, Mucedero M, Pavoni C, Franchi L. Treatment and posttreatment effects of a facial mask combined with a bite-block appliance in class III malocclusion. American Journal of Orthodontics and Dentofacial Orthopedics. 2010;138(3):300-310.

121. Turley PK. Managing the developing class III malocclusion with palatal expansion and facemask therapy. American Journal of Orthodontics and Dentofacial Orthopedics. 2002;122(4):349-352. 
122. Baccetti T, Franchi L, McNamara Jr JA. Treatment and posttreatment craniofacial changes after rapid maxillary expansion and facemask therapy. American Journal of Orthodontics and Dentofacial Orthopedics. 2000;118(4):404-413.

123. Macdonald KE, Kapust AJ, Turley PK. Cephalometric changes after the correction of class III malocclusion with maxillary expansion/facemask therapy. American Journal of Orthodontics and Dentofacial Orthopedics. 1999;116(1):13-24.

124. Wells AP. Long-term efficacy of reverse pull headgear therapy. Angle Orthod. 2006;76(6):915; 915922; 922.

125. Westwood PV, McNamara Jr. JA, Baccetti T, Franchi L, Sarver DM. Long-term effects of class III treatment with rapid maxillary expansion and facemask therapy followed by fixed appliances. American Journal of Orthodontics and Dentofacial Orthopedics. 2003;123(3):306-320. Accessed 6 April 2012.

126. Baccetti T, Franchi L, McNamara Jr. JA. Treatment and posttreatment craniofacial changes after rapid maxillary expansion and facemask therapy. American Journal of Orthodontics and Dentofacial Orthopedics. 2000;118(4):404-413. Accessed 6 April 2012.

127. Deguchi T. Very early face mask therapy in class III children. Angle Orthod. 1999;69(4):349.

128. Deguchi T, Kuroda T, Minoshima Y, Graber TM. Craniofacial features of patients with class III abnormalities: Growth-related changes and effects of short-term and long-term chincup therapy. American Journal of Orthodontics and Dentofacial Orthopedics. 2002;121(1):84-92. 
129. Sugawara J, Daimaruya T, Umemori M, Nagasaka H, Takahashi I, Kawamura H. Distal movement of mandibular molars in adult patients with the skeletal anchorage system. Am.J.Orthod.Dentofacial Orthop. 2004;125:130-138.

130. De Clerck H, Cevidanes L, Baccetti T. Dentofacial effects of bone-anchored maxillary protraction: A controlled study of consecutively treated class III patients. American Journal of Orthodontics and Dentofacial Orthopedics. 2010;138(5):577-581. doi: 10.1016/j.ajodo.2009.10.037.

131. Nguyen T, Cevidanes L, Cornelis MA, Heymann G, de Paula LK, De Clerck H. Three-dimensional assessment of maxillary changes associated with bone anchored maxillary protraction. American Journal of Orthodontics and Dentofacial Orthopedics. 2011;140(6):790-798. doi: 10.1016/j.ajodo.2011.04.025.

132. Kircelli BH, Pektas ZÖ. Midfacial protraction with skeletally anchored face mask therapy: A novel approach and preliminary results. American Journal of Orthodontics and Dentofacial Orthopedics. 2008;133(3):440-449.

133. Franchi L, Baccetti T, McNamara Jr JA. Postpubertal assessment of treatment timing for maxillary expansion and protraction therapy followed by fixed appliances. American Journal of Orthodontics and Dentofacial Orthopedics. 2004;126(5):555-568.

134. Takada K, Petdachai S, Sakuda M. Changes in dentofacial morphology in skeletal class III children treated by a modified maxillary protraction headgear and a chin cup: A longitudinal cephalometric appraisal. Eur J Orthod. 1993;15(3):211-221.

135. Cevidanes L. Comparison of two protocols for maxillary protraction: Bone anchors versus face mask with rapid maxillary expansion. Angle Orthod. 2010;80(5):799; 799-806; 806. 
136. Westwood PV, McNamara Jr JA, Baccetti T, Franchi L, Sarver DM. Long-term effects of class III treatment with rapid maxillary expansion and facemask therapy followed by fixed appliances. American Journal of Orthodontics and Dentofacial Orthopedics. 2003;123(3):306-320.

137. Cha BK. Skeletal changes of maxillary protraction in patients exhibiting class III malocclusion: A comparison of three skeletal maturation groups. Angle Orthodontist. 2003;73:26-35.

138. De Clerck H, Cevidanes L, Baccetti T. Dentofacial effects of bone-anchored maxillary protraction: A controlled study of consecutively treated class III patients. American Journal of Orthodontics and Dentofacial Orthopedics. 2010;138(5):577-581.

139. Heymann GC, Cevidanes L, Cornelis M, De Clerck HJ, Tulloch JFC. Three-dimensional analysis of maxillary protraction with intermaxillary elastics to miniplates. American Journal of Orthodontics and Dentofacial Orthopedics. 2010;137(2):274-284. doi: 10.1016/j.ajodo.2009.07.009.

140. Baccetti T, Franchi L, McNamara Jr. JA. The cervical vertebral maturation (CVM) method for the assessment of optimal treatment timing in dentofacial orthopedics. Semin Orthod. 2005;11(3):119-129.

141. Liou EJ, Pai BC, Lin JC. Do miniscrews remain stationary under orthodontic forces? American Journal of Orthodontics and Dentofacial Orthopedics. 2004;126(1):42-47. 
APPENDICES 


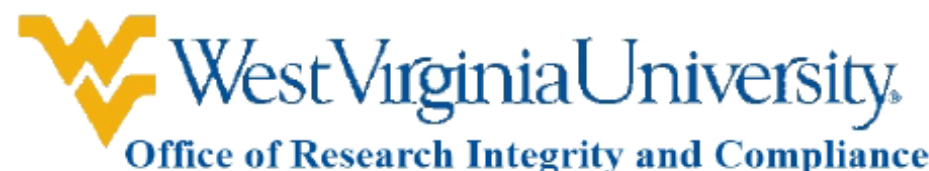

\section{Acknowledgement Letter Not Human Subject Research NHSR}

To

From

Approval Period

Subject

Protocol Tracking

Title
Peter Ngan

WVU Office of Research Integrity and Compliance

01/23/2014 Expiration Date 01/22/2019

Not Human Subject Research Acknowledgment

1401168542

Comparison of Two Protocols for Maxillary Protraction: Tooth Anchored versus Bone Anchored Protraction Facemask

Thank you for your submission to the West Virginia University Institutional Review Board IRB.

It has been determined that your project does not meet the definition of human subject research for the following reasons

- In order to be considered human subject research, individually identifiable private information must be obtained or used in the research. If there is no individually identifiable private information involved, the project is not human subject research and does not require being submitted to the Office of Research Integrity \& Compliance. Private information must be individually identifiable (i.e., the identity of the subject is or may be readily ascertained by the investigator or someone else associated with the information) in order to constitute research involving human subjects.

If you have any questions, please contact the IRB at 3042937073.

Thank you

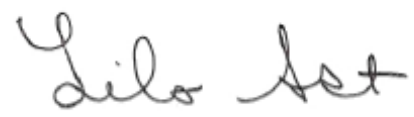

Board Designee Lilo Ast

Letter Sent By Lilo Ast on 01/23/2014 at 20:00:14-05:00 